NBER WORKING PAPER SERIES

\title{
MARGIN-BASED ASSET PRICING AND DEVIATIONS FROM THE LAW OF ONE PRICE
}

\author{
Nicolae Gârleanu \\ Lasse Heje Pedersen \\ Working Paper 16777 \\ http://www.nber.org/papers/w16777 \\ NATIONAL BUREAU OF ECONOMIC RESEARCH \\ 1050 Massachusetts Avenue \\ Cambridge, MA 02138 \\ February 2011
}

We are grateful for helpful comments from Markus Brunnermeier, Xavier Gabaix, Andrei Shleifer, and Wei Xiong, as well as from seminar participants at the Bank of Canada, Columbia GSB, Duke Fuqua, Harvard, London School of Economics, MIT Sloan, McGill University, Northwestern University Kellog, UT Austin McCombs, Yale University, UC Berkeley Haas, University of Chicago, McGill University, as well as conference participants at the Yale Financial Crisis Conference, the Society of Economic Dynamics, NBER Behavioral Economics, NBER Asset Pricing Summer Institute, NASDAQ OMX Derivatives Research Project Conference, the Econometric Society Winter Meeting, and the Western Finance Association Meetings. The views expressed herein are those of the authors and do not necessarily reflect the views of the National Bureau of Economic Research.

NBER working papers are circulated for discussion and comment purposes. They have not been peerreviewed or been subject to the review by the NBER Board of Directors that accompanies official NBER publications.

(C) 2011 by Nicolae Gârleanu and Lasse Heje Pedersen. All rights reserved. Short sections of text, not to exceed two paragraphs, may be quoted without explicit permission provided that full credit, including (c) notice, is given to the source. 
Margin-Based Asset Pricing and Deviations from the Law of One Price

Nicolae Gârleanu and Lasse Heje Pedersen

NBER Working Paper No. 16777

February 2011

JEL No. E02,E44,G01,G12,G13

\begin{abstract}
$\underline{\text { ABSTRACT }}$
In a model with heterogeneous-risk-aversion agents facing margin constraints, we show how securities' required returns are characterized both by their betas and their margin requirements. Negative shocks to fundamentals make margin constraints bind, lowering risk-free rates and raising Sharpe ratios of risky securities, especially for high-margin securities. Such a funding-liquidity crisis gives rise to "bases," that is, price gaps between securities with identical cash-flows but different margins. In the time series, bases depend on the shadow cost of capital, which can be captured through the interest-rate spread between collateralized and uncollateralized loans, and, in the cross section, they depend on relative margins. We test the model empirically using the CDS-bond bases and other deviations from the Law of One Price, and use it to evaluate central banks' lending facilities.
\end{abstract}

\author{
Nicolae Gârleanu \\ Haas School of Business \\ F628 \\ University of California, Berkeley \\ Berkeley, CA 94720 \\ and NBER \\ garleanu@haas.berkeley.edu \\ Lasse Heje Pedersen \\ NYU Stern Finance \\ 44 West Fourth Street \\ Suite 9-190 \\ New York, NY 10012 \\ and NBER \\ lpederse@stern.nyu.edu
}


The paramount role of funding constraints becomes particularly salient during liquidity crises, with the one that started in 2007 being an excellent case in point. Banks unable to fund their operations closed down, and the funding problems spread to other investors, such as hedge funds, that relied on bank funding. Therefore, traditional liquidity providers became forced sellers, interest-rate spreads increased dramatically, Treasury rates dropped sharply, and central banks stretched their balance sheets to facilitate funding. These funding problems had significant asset-pricing effects, the most extreme example being the failure of the Law of One Price: securities with (nearly) identical cash flows traded at different prices, giving rise to so-called "bases" (i.e., price gaps).

We attempt to explain these effects using a dynamic general-equilibrium model with realistic margin constraints, and to empirically test the model's time-series and cross-sectional predictions of how funding problems affect risk and return:

Our model shows that 1 ) the consumption CAPM is augmented by a security's margin times the general funding cost; 2) a basis between a security and a derivative with identical cash flows arises as the difference in their margin requirements times the funding cost, plus their endogenous difference in beta; 3) securities with higher margins have larger betas and volatilities during crises since they have larger funding liquidity risk; 4) the funding cost can be captured by the interest-rate differential between collateralized and uncollateralized borrowing; 5) the margin effect strengthens non-linearly in "bad times" as margin requirements are hit, leading to sharp drops in the risk-free collateralized and Treasury rates, to a rise in the spread between collateralized and uncollateralized interest rates, and to a rise in risk premia and especially margin premia; and 6) we calculate the equilibrium and calibrate the magnitude and dynamics of the bases using macro parameters.

In our applications, we 7) find statistically significant empirical evidence consistent with the model's predictions for the time-series of the CDS-bond basis, the cross-sectional difference between investment-grade and high-yield bases, and the risks of CDS vs. bonds and the time-variation of these risks; 8) find consistent evidence from the failure of the covered interest rate parity; 9) compute the asset-pricing effect of the Fed's lending facilities; and 10) quantify a bank's incentive to perform regulatory arbitrage to loosen capital requirements.

Our model considers a group of (relatively) risk-averse agents and a group of (relatively) risk-tolerant agents. Each risk-tolerant investor uses leverage, but is subject to margin requirements. He must fund all the margins on his positions with his equity capital and, possibly, uncollateralized loans. One can think of these leveraged investors as banks or the financial sector more broadly, including hedge funds. The risk-averse investors may be constrained in their trading of derivatives and cannot lend uncollateralized, so the uncollateralized loan market is a pure "inter-bank market" for the risk-tolerant investors.

We first show how margin requirements affect the required returns for both underlying assets and derivatives. ${ }^{1}$ For a typical asset in which the risk-tolerant agents hold long

\footnotetext{
${ }^{1}$ If there were no redundant securities and margins were constant over time, the result for the underlying assets would specialize a result in Cuoco (1997) for general convex portfolio constraints, and it is also closely related to results in Aiyagari and Gertler (1999) and Hindy and Huang (1995).
} 
positions in equilibrium, the required excess return $E\left(r^{i}\right)$ is

$$
E\left(r^{i}\right)=r^{\text {risk-free }}+\beta^{i} \times \text { covariance risk premium }+m^{i} \times \text { margin premium },
$$

where $m^{i}$ is the margin requirement (and all quantities may be time varying). The first two terms in this "margin CAPM" are the same as the standard (consumption) CAPM, namely the risk-free interest rate and the covariance risk premium. Hence, if the margin requirements are zero, our model naturally nests the standard model. With positive margin requirements — as in the real world - a security's required returns is higher, the higher its margin requirement. The margin premium is the shadow cost of funding for the risktolerant agents multiplied by the relative importance of these agents. Consequently, it is positive when margin constraints are binding, and zero otherwise. For instance, supposing that in a crisis the risk-tolerant investors have a shadow cost of capital of $10 \%$ (consistent with our estimates during the height of the Global Financial Crisis and with our calibration) and the risk-tolerant investors account for $40 \%$ of the aggregate risk tolerance, the margin premium is $4 \%$. Therefore, if a security has a margin requirement of $50 \%$, then its required return is $4 \% \times 50 \%=2 \%$ higher than the level predicted by the standard consumption CAPM, a significant effect.

Our model suggests that constrained investors would evaluate securities based on a ratio that we call alpha per margin (AM):

$$
A M^{i}=\frac{E\left(r^{i}\right)-r^{\text {risk-free }}-\beta^{i} \times \text { covariance risk premium }}{m^{i}} .
$$

This is the abnormal return (in excess of the risk-free rate and the standard risk adjustment) on a strategy of investing a maximally leveraged dollar in the asset. Hence, the margin CAPM in (1) can be stated equivalently by saying that, in equilibrium, all assets have the same alpha-per-margin, $A M^{i}=$ margin premium. While in the classical CAPM alpha is zero for all assets, in our model alphas can be non-zero when capital constraints bind, and AM ratios are equalized as investors seek to maximize their leveraged return.

We show that "bad times" with binding margin constraints naturally occur after negative shocks to fundamentals. This phenomenon leads to several intriguing effects. First, risk-free interest rates for collateralized loans and Treasuries spike down. This happens because the risk-tolerant agents cannot borrow as much as they would like due to margin constraints and, therefore, in equilibrium the risk-averse agents must lend less than they otherwise would. In order to induce the risk-averse agents not to lend, the interest rate must drop.

Further, in bad times the spread between the inter-bank uncollateralized loans and the collateralized loans (or Treasuries) increases, even abstracting from credit risk. This liquiditydriven interest-rate premium arises from the fact that the risk-averse investors do not participate in the uncollateralized inter-bank market. Since the risk-tolerant banks are constrained, the inter-bank interest rate must be greater than the Treasury rate to reflect the banks' positive shadow cost of capital. While this pure liquidity-driven interest-rate spread is zero in "normal" times when margin requirements do not bind, it increases non-linearly following negative shocks as when the crisis hit in 2007, as well as in previous liquidity crisis. 
Hence, the deviation from the standard CAPM is most apparent in "bad times," when the funding-liquidity effects are the strongest. A stark illustration of this margin-based assetpricing effect is the price difference between securities with the same cash flows but different margin requirements. We show that the required return on a high-margin security - e.g., a corporate bond - is greater than that of a low-margin security with the same cash flows e.g., proxied by a CDS. This is because of the high shadow cost of capital of the risk tolerant investor. When the risk tolerant investor's margin constraint binds, he is willing to accept a lower yield spread on a CDS since it uses less margin capital.

As empirical evidence of this prediction, we find that the time-series variation of the CDSbond basis has a statistically significant co-movement with the LIBOR-GC repo interest-rate spread (i.e., the spread between uncollateralized and collateralized loans), as well as the tightness of credit standards as estimated by the Federal Reserve Board's "Senior Loan Officer Opinion Survey on Bank Lending Practices."

The model predicts that the magnitude of the basis is the shadow cost of capital times the margin difference plus the difference in betas. To understand this predicted magnitude, consider the CDS-bond basis, that is, the yield difference between a corporate bond and a comparable derivative. With a shadow cost of capital of $10 \%$ during the crisis, a margin on investment grade bonds of $25 \%$, and a margin on the corresponding CDS of $5 \%$, the direct effect of the margin difference on the basis is $10 \% \times(25 \%-5 \%)=2 \%$, close to what was observed empirically. Additionally, the model predicts that the corporate bond's higher margin makes it riskier since it is more sensitive to further funding crisis, leading to an additional, albeit smaller, effect on the basis.

When there are several pairs of underlying/derivative securities, each of which having an associated basis, our model predicts that these bases are correlated in the time series due to their common dependence on the shadow cost of capital, and, cross-sectionally, the bases should be proportional to each pair's difference in margin requirements.

To test these cross-sectional predictions empirically, we compare the basis of investmentgrade (IG) bonds with the basis for high-yield (HY) bonds and find that they move closely together and that the difference in their magnitudes corresponds to the difference in their margins, consistent with our model's prediction. Indeed, the margin difference between HY bonds and CDS is about twice that of IG bonds/CDS, so the model predicts a HY basis effect that is about twice the IG basis, consistent with the data.

Interestingly, the model also implies that securities with identical cash flows but different margins have different risk characteristics due to their different exposures to funding-liquidity risk. The low-margin CDS has less systematic risk since its price drops less in liquidity crisis, and, therefore, its required return is lower even before the margin constraint binds. Consistent with the model, we find empirically that bonds and CDS have similar betas and volatilities during "normal" times when constraints are not near being binding, but that betas and volatilities of high-margin bonds rise above those of CDSs during the 2007-2009 liquidity crisis.

Further consistent evidence arises from the related time-series variation of the interestrate spread and that of the deviation from the covered interest parity (CIP). Indeed, during 
the funding crises of 1998 and 2007-2009, when margins are likely to have been binding, interest-rate spreads were wide and the CIP deviation was substantial since agents did not have enough capital to eliminate it.

As another application of the model, we show how the Fed's lending facilities affect asset prices, providing new insights on the monetary transmission mechanism during liquidity. We discuss how the lending facilities lower margin requirements, and show that the modelimplied increase in asset prices is of the same order of magnitude as the increase attributable to lowered margins in the banks' bid prices, according to surveys conducted by the Federal Reserve Bank of New York.

Further, we derive the shadow cost of banks' regulatory-capital requirements, which gives an estimate of their incentive to perform regulatory arbitrage by placing assets off the balance sheet or tilting towards AAA securities with low capital requirements.

The paper is related to a number of strands of literature. Borrowing constraints confer assets a collateral value (Bernanke and Gertler (1989), Hindy (1995), Detemple and Murthy (1997), Geanakoplos (1997), Kiyotaki and Moore (1997), Caballero and Krishnamurthy (2001), Lustig and Van Nieuwerburgh (2005), Coen-Pirani (2005), and Fostel and Geanakoplos (2008)) and constraints open the possibility of arbitrage in equilibrium (Basak and Croitoru (2000, 2006) and Geanakoplos (2003)). We focus on margin requirements, which are linked to market liquidity and volatility (Gromb and Vayanos (2002), Brunnermeier and Pedersen (2009), Adrian and Shin (2009), Danielsson, Shin, and Zigrand (2009), and Rytchkov (2009)), and provide analytic asset-pricing effects. Asset prices also depend on market liquidity (Amihud and Mendelson (1986), Longstaff (2004), Duffie, Gârleanu, and Pedersen (2007), and Gârleanu, Pedersen, and Poteshman (2009)), market liquidity risk (Acharya and Pedersen (2005), Mitchell, Pedersen, and Pulvino (2007), and He and Krishnamurthy (2008)), limits to arbitrage (Shleifer and Vishny (1997)), banking frictions (Allen and Gale (1998, 2004, 2005), Acharya and Viswanathan (2010)), and related corporate-finance issues (Holmström and Tirole $(1998,2001))$. We use the methods for analyzing equilibria in continuous-time models with constraints of Cuoco (1997); other related applications are provided by Li (2008), Rytchkov (2009), Chabakauri (2010), and Prieto (2010). ${ }^{2}$

The specification of the margin requirement is key to our results. First, we make the realistic assumption that both long and short positions use capital; in contrast, a linear constraint, as often assumed in the literature, implies that shorting frees up capital. While bases with natural properties arise in our model, we show that no basis can obtain in a world in which all agents face only the same linear constraint. Second, we consider assets with identical cash flows and different margin requirements, while margins for such assets would be the same if margins arose solely from limited commitment (Geanakoplos (1997)). In the real world, securities with (almost) identical cash flows can have substantially different margins, since margins depend on the market liquidity of the securities (Brunnermeier and Pedersen (2009)) and because of various institutional frictions. For instance, corporate bonds have low

\footnotetext{
${ }^{2}$ Numerous papers study frictionless heterogeneous-agent economies, e.g., Dumas (1989), Wang (1996), Chan and Kogan (2002), Bhamra and Uppal (2007), Weinbaum (2009), Gârleanu and Panageas (2008), and Longstaff and Wang (2009).
} 
market liquidity in over-the-counter search markets (Duffie, Gârleanu, and Pedersen (2005, 2007), Vayanos and Weill (2008)) and this makes them less attractive as collateral since they can be difficult to sell. Further, to get credit exposure through a corporate bond, one must actually buy the bond for cash and try to fund it using a repo, which uses a broker's balance sheet, while a CDS is an "unfunded" derivative with zero net present value, so the margin is only necessary to limit counterparty risk; the CDS does not inherently use cash. Our model further allows for time-varying margins, given that margins tend to increase during crises due to a margin spiral as explained by Brunnermeier and Pedersen (2009) and documented empirically by Gorton and Metrick (2009a, 2009b).

We complement the literature by providing a tractable model with explicit pricing equations that provide testable time-series and cross-sectional implications, deriving the basis (i.e., price gap) between securities with identical cashflows depending on their different margins, showing how the shadow cost of funding can be captured using interest-rate spreads, calibrating the magnitude and dynamics of the predicted deviations from the Law of One Price using realistic parameters, testing the theory empirically using the CDS-bond basis and the failure of the CIP, and applying the theory to the Federal Reserve's lending facilities and the incentive to perform regulatory arbitrage.

The rest of the paper is organized as follows. Section 1 lays out the model, Section 2 derives our main theoretical results and calibrates the model, and Section 3 applies the model empirically to the CDS-bond basis, the failure of the covered interest rate parity, and the pricing of the Fed's lending facilities, and quantifies the cost of banks' regulatory capital requirements. Section 4 concludes.

\section{$1 \quad$ Model}

We consider a continuous-time economy in which several risky assets are traded. Each asset $i$ pays a dividend $\delta_{t}^{i}$ at time $t$ and is available in a supply normalized to 1 . The dividend of each security $i$ is a continuous Itô process driven by a multi-dimensional standard Brownian motion $w:^{3}$

$$
d \delta_{t}^{i}=\delta_{t}^{i}\left(\mu_{t}^{\delta^{i}} d t+\sigma_{t}^{\delta^{i}} d w_{t}\right)
$$

where $\mu_{t}^{\delta^{i}}$ is the dividend growth and the dividend volatility is given by the vector $\sigma_{t}^{\delta^{i}}$ of loadings on the Brownian motion.

Each security is further characterized by its margin (also called a haircut) $m_{t}^{i} \in[0,1]$, an Itô process, measured as a fraction of the investment that must be financed by an agent's own capital as discussed below. For instance, the margin on a corporate bond could be $m_{t}^{\text {bond }}=50 \%$, meaning that an agent can borrow half of the value and must pay the other half using his own capital.

\footnotetext{
${ }^{3}$ All random variables are defined on a probability space $(\Omega, \mathcal{F})$ and all processes are measurable with respect to the augmented filtration $\mathcal{F}_{t}^{w}$ generated by $w$.
} 
In addition to these "underlying assets" in positive supply, the economy has a number of "derivatives" in zero net supply. Each derivative $i^{\prime}$ has the same cash flows $\delta_{t}^{i}$ as some underlying security $i$, but with a lower margin requirement: $m_{t}^{i^{\prime}}<m_{t}^{i}$.

We assume that the prices of underlying assets and derivatives are Itô processes with expected return (including dividends) denoted $\mu_{t}^{i}$ and volatility vectors $\sigma_{t}^{i}$, which are linearly independent across the underlying assets:

$$
d P_{t}^{i}=\left(\mu_{t}^{i} P_{t}^{i}-\delta_{t}^{i}\right) d t+P_{t}^{i} \sigma_{t}^{i} d w_{t} .
$$

Finally, the set of securities includes two riskless money-market assets, one for collateralized loans and one for uncollateralized loans as explained further below. The equilibrium interest rate for collateralized loans is $r_{t}^{c}$ and for uncollateralized loans is $r_{t}^{u}$.

The economy is populated by two agents: agent $a$ is averse to risk, whereas $b$ is braver. Specifically, agent $g \in\{a, b\}$ maximizes his utility for consumption given by

$$
E_{t} \int_{0}^{\infty} e^{-\rho s} u^{g}\left(C_{s}\right) d s
$$

where $u^{a}(C)=\frac{1}{1-\gamma^{a}} C^{1-\gamma^{a}}$ with relative risk aversion $\gamma^{a}>1$, and $u^{b}(C)=\log (C)$ with relative risk aversion $\gamma^{b}=1$. We can think of agent $a$ as a representative pension fund or risk-averse private (retail) investor, and of agent $b$ as representing more risk-tolerant investors using leverage such as banks or hedge funds.

At any time $t$, each agent $g \in\{a, b\}$ must choose his consumption, $C_{t}^{g}$ - we omit the superscript $g$ when there is little risk of confusion - the proportion $\theta_{t}^{i}$ of his wealth $W_{t}$ that he invests in risky asset $i$, and the proportion $\eta_{t}^{u}$ invested in the uncollateralized loans; the rest is invested in collateralized loans. The agent must keep his wealth positive, $W_{t} \geq 0$, and the wealth evolves according to

$$
d W_{t}=\left(W_{t}\left(r_{t}^{c}+\eta_{t}^{u}\left(r_{t}^{u}-r_{t}^{c}\right)+\sum_{i} \theta_{t}^{i}\left(\mu_{t}^{i}-r_{t}^{c}\right)\right)-C_{t}\right) d t+W_{t} \sum_{i} \theta_{t}^{i} \sigma_{t}^{i} d w_{t}
$$

where the summation is done over all risky underlying and derivative securities.

Each agent faces a margin constraint that depends on the securities' margins $m_{t}^{i}$ :

$$
\sum_{i} m_{t}^{i}\left|\theta^{i}\right|+\eta^{u} \leq 1
$$

In words, an agent can tie up his capital in margin for long or short positions in risky assets and invest in uncollateralized loans (or borrow uncollateralized if $\eta^{u}<0$ ), and these capital uses, measured in proportion of wealth, must be less than $100 \%$ of the wealth. The rest of the wealth, as well as the money in margin accounts, earn the collateralized interest rate. ${ }^{4}$

\footnotetext{
$$
\sum_{i}\left|\theta^{i}\right|+\eta^{u} \leq 1+\sum_{i}\left|\theta^{i}\right| l^{i}
$$
}

${ }^{4}$ Alternatively, the constraint can be written as 
This key constraint is a main driver of our results. The literature often assumes a linear margin constraint (i.e., without the absolute-value operator), but Appendix A shows that deviations from the Law of One Price cannot arise in this case. Our constraint captures well the problem facing any real-world investor (e.g., real-world investors cannot finance unlimited long positions by short ones as is implied by the linear constraint) and it gives rise to deviations from the Law of One Price that match those observed empirically.

In addition, the risk-averse agent $a$ does not participate in the markets for uncollateralized loans and may be allowed only limited positions in derivatives. That is, he must choose $\eta^{u}=0$ and $\theta^{i^{\prime}} \in \mathcal{A}^{i^{\prime}}$ for every derivative $i^{\prime}$, where the admissible set $\mathcal{A}^{i^{\prime}}$ can, for instance, be specified as $\mathcal{A}^{i^{\prime}}=\{0\}$, meaning that he cannot trade derivatives, or as $\mathcal{A}^{i^{\prime}}=[\underline{\mathcal{A}}, \overline{\mathcal{A}}]$, meaning that he can only trade a limited amount. This captures the fact that certain agents are often limited both by risk aversion and a lack of willingness to participate in some transactions, e.g., those with apparent operational risk - i.e., the risk that something unspecified can go wrong - and by a lack of expertise. Also, this means that the uncollateralized market may capture an inter-bank loan market.

Our notion of equilibrium is standard. It is a collection of prices, consumption plans, and positions, such that (i) each agent maximizes his utility given the prices and subject to his investment constraints; (ii) the markets for risky and risk-free assets clear.

\section{Margin-Based Asset Prices}

We are interested in the properties of the equilibrium and consider first the optimization problem of the brave agent $b$ using dynamic programming. The logarithmic utility for consumption implies that the Hamilton-Jacobi-Bellman equation reduces to the myopic meanvariance maximization

$$
\max _{\theta_{t}^{i}, \eta_{t}^{u}}\left\{r_{t}^{c}+\eta_{t}^{u}\left(r_{t}^{u}-r_{t}^{c}\right)+\sum_{i} \theta_{t}^{i}\left(\mu_{t}^{i}-r_{t}^{c}\right)-\frac{1}{2} \sum_{i, j} \theta_{t}^{i} \theta_{t}^{j} \sigma_{t}^{i}\left(\sigma_{t}^{j}\right)^{\top}\right\}
$$

subject to the margin constraints $\sum_{i} m_{t}^{i}\left|\theta_{t}^{i}\right|+\eta_{t}^{u} \leq 1$.

Attaching a Lagrange multiplier $\psi$ to the margin constraint, the first-order condition with respect to the uncollateralized investment or loan $\eta^{u}$ yields the following result:

Proposition 1 (Interest-Rate Spread) The interest-rate differential between uncollateralized and collateralized loans captures the risk tolerant agent's shadow cost of an extra dollar of funding, $r_{t}^{u}-r_{t}^{c}=\psi_{t}$.

For a long position, $l^{i}$ is the proportion of the security value that can be borrowed in the collateralized lending market (e.g., the repo market). Hence, the left-hand-side of the equation is the fraction of wealth $\theta^{i}$ used to buy the security, and the right-hand-side is the total wealth 1 plus the borrowed amount $\theta^{i} l^{i}$. Naturally, the margin $m^{i}=1-l^{i}$ is the fraction of the security value that cannot be borrowed against.

For a short position, one must first borrow the security and post cash collateral of $\left(1+m^{i}\right) \theta^{i}$ and, since the short sale raises $\theta^{i}$, the net capital use is $m^{i} \theta^{i}$. Derivatives with zero net present value have margin requirements too. See Brunnermeier and Pedersen (2009) for details. 
The proposition identifies the shadow cost of capital, central to our asset-pricing analysis, as the interest-rate differential between uncollateralized loans, which do not use up a borrower's potentially scarce collateral, and collateralized loans, which do. In addition to having intuitive appeal, this relationship is valuable for linking the unobserved shadow cost of capital $\psi$ to quantities in principle observable; we use it in our empirical analysis.

Agent $b$ 's first-order condition with respect to the risky-asset position $\theta^{i}$ is

$$
\begin{array}{ll}
\mu_{t}^{i}-r_{t}^{c}=\beta_{t}^{C^{b}, i}+\psi_{t} m_{t}^{i} & \text { if } \quad \theta^{i}>0 \\
\mu_{t}^{i}-r_{t}^{c}=\beta_{t}^{C^{b}, i}-\psi_{t} m_{t}^{i} & \text { if } \quad \theta^{i}<0 \\
\mu_{t}^{i}-r_{t}^{c}=\beta_{t}^{C^{b}, i}+y_{t}^{i} \psi_{t} m_{t}^{i} \quad \text { with } y_{t}^{i} \in[-1,1] & \text { if } \quad \theta^{i}=0,
\end{array}
$$

where we simplify notation by letting

$$
\beta_{t}^{C^{b}, i}=\operatorname{cov}_{t}\left(\frac{d C^{b}}{C^{b}}, \frac{d P^{i}}{P^{i}}\right)
$$

denote the conditional covariance between agent $b$ 's consumption growth and the return on security $i$. These first-order conditions mean that a security's expected excess return $\mu_{t}^{i}-r_{t}^{c}$ depends on its margin $m_{t}^{i}$, the risk tolerant agent's shadow cost of funding $\psi_{t}$, and the security's covariance with the risk tolerant agent's consumption growth.

To characterize the way in which returns depend on aggregate consumption (which is easier to observe empirically), we also need to consider agent $a$ 's optimal policy and aggregate across agents. ${ }^{5}$ If $a$ 's margin requirement does not bind, standard arguments show that the underlying securities are priced by his consumption, $\mu^{i}-r^{c}=\gamma^{a} \beta^{C^{a}, i}$, but the general problem with margin constraints and spanned securities is more complex. In the general case, we derive a consumption CAPM (CCAPM) depending on aggregate consumption in the appendix. For this, we first introduce some notation: $\beta_{t}^{C, i}$ is the covariance of the growth in the aggregate consumption $C=C^{a}+C^{b}$ and the return of security $i$,

$$
\beta_{t}^{C, i}=\operatorname{cov}_{t}\left(\frac{d C}{C}, \frac{d P^{i}}{P^{i}}\right),
$$

and $\gamma_{t}$ is the "representative" agent's risk aversion, i.e.,

$$
\frac{1}{\gamma_{t}}=\frac{1}{\gamma^{a}} \frac{C_{t}^{a}}{C_{t}^{a}+C_{t}^{b}}+\frac{1}{\gamma^{b}} \frac{C_{t}^{b}}{C_{t}^{a}+C_{t}^{b}} .
$$

The fraction $x_{t}$ of the economy's risk-bearing capacity due to agent $b$ is

$$
x_{t}=\frac{\frac{C_{t}^{b}}{\gamma^{b}}}{\frac{C_{t}^{a}}{\gamma^{a}}+\frac{C_{t}^{b}}{\gamma^{b}}} .
$$

\footnotetext{
${ }^{5}$ See Proposition 3 in Cuoco (1997) for a CAPM relation for general time-invariant convex portfolio constraints in the absence of redundant securities.
} 
We recall that $\psi$ is agent $b$ 's shadow cost of funding. With these definitions, we are ready to state the margin-adjusted CCAPM and CAPM. For simplicity, we do it under the natural assumption that the margin constraint of the risk-averse agent $a$ does not bind. ${ }^{6}$

Proposition 2 (Margin CCAPM) The expected excess return $\mu_{t}^{i}-r_{t}^{c}$ on an underlying asset that agent $b$ is long is given by the standard consumption CAPM adjusted for funding costs:

$$
\mu_{t}^{i}-r_{t}^{c}=\gamma_{t} \beta_{t}^{C, i}+x_{t} \psi_{t} m_{t}^{i}
$$

If agent $b$ is short the asset, then the funding-liquidity term is negative, i.e., $\mu_{t}^{i}-r_{t}^{c}=$ $\gamma_{t} \beta_{t}^{C, i}-x_{t} \psi_{t} m_{t}^{i}$, while if $b$ has a zero position the required return lies between the two values.

This proposition relates excess returns to the covariance between aggregate consumption growth and a security's returns, as well as to the funding constraints. The covariance term is the same as in the classic CCAPM model of Breeden (1979). The difference is the funding term, which is the product of the security-specific margin $m_{t}^{i}$ and the general coefficients $\psi_{t}$ and $x_{t}$ that measure the tightness of the margin constraints. Naturally, the tightness of the margin constraint depends on the leveraged risk-tolerant agent's shadow cost of funding, $\psi$, and the relative importance of this agent, $x$.

The margin-CCAPM's economic foundation dictates the magnitude of the coefficients. Since $\gamma^{b}=1$ and $\gamma^{a}$ is a number between 1 and 10, say, the aggregate risk aversion $\gamma_{t}$ is somewhere between 1 and 10, and varies over time depending on the agents' relative wealths. The relative importance $x$ of agent $b$ is a number between 0 and 1 . While this risk-tolerant agent might be a small part of the economy in terms of total consumption or wealth, his risk tolerance is larger, which raises his importance. For instance, even if we think that he accounts only for as little as $2 \%$ of the aggregate consumption, and if agent $a$ has a risk aversion of 10 , then $x$ is around $17 \%$, close to 10 times the consumption share. The shadow cost $\psi$ can be as much as $10 \%$ in our calibration and empirical analysis. Hence, for a security with a $50 \%$ margin, the funding term would raise the required return by $17 \% \times 10 \% \times 50 \% \approx 1 \%$ in this case.

For a different way to interpret relationship (14), consider the "alpha" of asset $i$, that is, the expected excess return adjusted for risk, $\alpha_{t}^{i}=\mu_{t}^{i}-r_{t}^{c}-\gamma_{t} \beta_{t}^{C, i}$. The Margin CCAPM says that alphas are proportional to margin requirements, $\psi x_{t} m_{t}^{i}$, or, if we introduce the ratio alpha per margin $(A M)$, it says that $A M^{i}$ is constant across securities $i$,

$$
A M_{t}^{i}=x_{t} \psi_{t}
$$

For instance, if a security has a margin requirement of $10 \%$, it can be leveraged 10-to- 1 . In this case, $A M^{i}=10 \times \alpha$ must equal the aggregate shadow cost of capital $x_{t} \psi_{t}$ to make it worthwhile for the agents to use margin equity to hold this security.

\footnotetext{
${ }^{6}$ We state and prove the propositions without this assumption in the appendix, but focus on this case because it is natural, simpler to state, and obtains in our calibrated equilibrium in Section 2.1. In the general case, (B.1) contains the additional term that captures $a$ 's margin constraint, $+\left(1-x_{t}\right) \bar{\psi}_{t}$, where $\bar{\psi}_{t}$ is $a$ 's shadow cost of capital, and similarly for (16).
} 
The CAPM can also be written in terms of a mimicking portfolio in place of the aggregate consumption. Specifically, let $q$ be the portfolio whose return has the highest possible (instantaneous) correlation with aggregate consumption growth and $q_{t}^{i}$ be the weight of asset $i$ in this portfolio. Further, any asset $i$ 's return beta to portfolio $q$ is denoted by $\beta_{t}^{i}$, i.e.,

$$
\beta_{t}^{i}=\frac{\operatorname{cov}_{t}\left(\frac{d P^{q}}{P^{q}}, \frac{d P^{i}}{P^{i}}\right)}{\operatorname{var}_{t}\left(\frac{d P^{q}}{P^{q}}\right)} .
$$

Proposition 3 (Margin CAPM) Suppose that the margin constraint of agent a does not bind. The expected excess return $\mu_{t}^{i}-r_{t}^{c}$ on an underlying asset that $b$ is long is

$$
\mu_{t}^{i}-r_{t}^{c}=\lambda_{t}^{\beta} \beta_{t}^{i}+x_{t} \psi_{t} m_{t}^{i}
$$

where $\lambda_{t}$ is a covariance risk premium. If $b$ is short, then the margin term is negative, i.e., $\mu_{t}^{i}-r_{t}^{c}=\lambda_{t}^{\beta} \beta_{t}^{i}-x_{t} \psi_{t} m_{t}^{i}$, and otherwise the required return lies between the two values.

We next turn to the basis between underlying securities and derivatives. The optimization problem of the brave agent $b$ implies the following relation for the basis.

Proposition 4 (Basis) A basis arises when b's margin constraint binds and a's derivativetrading constraint or margin constraint binds. Depending on the constraints, the basis is influenced by the difference or sum of margins:

(A. Levered Investor Causing Basis) Suppose that agent $b$ is long security $i$ and long derivative $i^{\prime}$. Then the required return spread $\mu_{t}^{i}-\mu_{t}^{i^{\prime}}$ between security $i$ and derivative $i^{\prime}$ (the "basis") depends on the shadow cost of capital $\psi$, the securities' difference in margins, $m_{t}^{i}-m_{t}^{i^{\prime}}$, and the difference in their covariance with the consumption of the brave agent $b$ through

$$
\mu_{t}^{i}-\mu_{t}^{i^{\prime}}=\psi_{t}\left(m_{t}^{i}-m_{t}^{i^{\prime}}\right)+\left(\beta_{t}^{C^{b}, i}-\beta_{t}^{C^{b}, i^{\prime}}\right) .
$$

(B. Levered Investor Reducing Basis) If agent $b$ is long $i$ and short derivative $i^{\prime}$, then the basis equals

$$
\mu_{t}^{i}-\mu_{t}^{i^{\prime}}=\psi_{t}\left(m_{t}^{i}+m_{t}^{i^{\prime}}\right)+\left(\beta_{t}^{C^{b}, i}-\beta_{t}^{C^{b}, i^{\prime}}\right) .
$$

This proposition provides useful intuition about the drivers of a basis. Since a non-zero basis constitutes a failure of the Law of One Price, all agents must be constrained for this to happen in equilibrium. Such a situation obtains when the risk-tolerant agent $b$ is constrained by his leverage and agent $a$ is constrained by his limited ability to hold derivatives.

If the risk-averse investor can short only a limited amount of derivatives, then case A in the proposition arises. In this case, the risk-tolerant investor $b$ wants to go long both the underlying and the derivative to earn the associated risk premium. He can get exposure to the derivative with less use of margin, and, therefore, he is willing to accept a smaller return premium on the derivative. In fact, the basis as measured by the return spread is 
the difference in margins multiplied by the shadow cost of capital, adjusted for the beta difference.

The second case obtains, for instance, if agent $a$ has a structural need - for some institutional reason — to hold a long position in the derivative, i.e., $\mathcal{A}^{i^{\prime}}=\left\{A^{i^{\prime}}\right\}$, where $A^{i^{\prime}}>0$. This creates a demand pressure on the derivative, and, in equilibrium, agent $b$ will do a basis trade, that is, shortsell the derivative and go long the underlying. The basis trade uses margin on both the long and the short side, and therefore the basis depends on the sum of the margins $m_{t}^{i}+m_{t}^{i^{\prime}}$ times the shadow cost of capital.

Proposition 4 provides natural empirical predictions that we consider in Section 3: First, the basis varies in the time series with the scarcity of funding $\psi$, which is related to the interest-rate spread (Proposition 1). Second, the basis varies with margins in the crosssection of bases for the various security/derivative pairs.

It is interesting that the returns of the underlying security and its derivative may have different sensitivities to underlying shocks and, therefore, can have different covariances with the brave agent's consumption. The different sensitivities to funding shocks are due to their different margin requirements. In particular, if a security has a lower margin requirement, then it is less sensitive to a funding crisis where margin constraints become binding, and it therefore has a lower $\beta^{C^{b}, i^{\prime}}$, as our calibrated example in Section 2.2 illustrates.

Since margins do affect betas in general, however, it is not immediate from Proposition 4 that higher margins increase the required return and, hence, lower prices. It is nevertheless the case that higher margin requirements translate into lower prices under certain conditions, as we show next.

Proposition 5 If assets $i$ and $j$ have identical cashflows, $i$ always has a higher margin requirement $m_{t}^{i}>m_{t}^{j}$, and agent $b$ is long both assets a.e., then $i$ has a lower price $P_{t}^{i} \leq P_{t}^{j}$. The inequality is strict if the margin constraint binds with positive probability after time $t$.

This result follows from the fact that the price of a security can be expressed as the sum of its cashflows discounted using an agent's marginal utility, and its collateral value, which depends monotonically on $m$. Another way to see this result is to express the price as the discounted sum of all future cashflows, where the discount factor depends both on the marginal utility and on margins (times the shadow cost of capital), so that higher margins imply a larger discount rate.

\subsection{Calculating the Equilibrium with Many Assets}

We next consider a simplified economy in which we can compute the equilibrium directly. This provides further intuition and allows us to calibrate the economy using realistic macroeconomic parameters. The economy has a continuum of assets, each available in an infinitesimal net supply of 1 . The dividend paid by asset $i$ is given by a share $s^{i}$ of the aggregate dividend, $\delta^{i}=s^{i} C$, with

$$
\begin{aligned}
d C_{t} & =\mu^{C} C_{t} d t+\sigma^{C} C_{t} d w_{t} \\
d s_{t}^{i} & =\sigma^{s^{i}} s_{t}^{i} d w_{t}^{i},
\end{aligned}
$$


where the standard Brownian motions $w$ and $w^{i}$ are independent. The dividend share is initiated at $s_{0}^{i}=1$ and it is a martingale since its drift is zero. We appeal informally to the Law of Large Numbers (LLN) to state $\mathrm{E}_{t}\left[s_{v}^{i} \mid i \in I\right]=1, \forall v \geq t \geq 0$ and for any interval $I \subseteq[0,1]$. In particular, the aggregate dividend naturally equals $\mathrm{E}\left[\delta_{t}^{i} \mid C_{t}\right]=C_{t}$. All the underlying assets have the same margin requirement $m^{i}=m$, and there are derivatives in zero net supply with different margins $m^{i^{\prime}} \leq m$ as before. The averse agent $a$ 's derivativetrading constraint is simple: he cannot participate in any derivative market.

The LLN implies that the idiosyncratic factors $s^{i}$ are not priced and, therefore, the price of any underlying security $i$ is $P^{i}=s^{i} P$, where $P$ is the price of the market, which is the same as in an economy with a single asset paying dividend $C$ and having margin $m$. We therefore concentrate on pricing this market asset.

To calculate an equilibrium, we use the fact that agent $b$ 's consumption is his discount rate $\rho$ times his wealth, $C^{b}=\rho W^{b}$ (as is well-known for log-utility agents). This means that agent $b$ 's consumption as a fraction of the total consumption, $c^{b}=C^{b} / C$, characterizes the wealth distribution and becomes a convenient state variable to keep track of. Further, "level" variables are linear in the aggregate consumption $C$ since it is a geometric Brownian motion and utilities are isoelastic. Hence, we are looking for an equilibrium in which the state is summarized by $\left(C, c^{b}\right)$, where stock prices and wealths scale linearly with $C$ for fixed $c^{b}$, while interest rates, Sharpe ratios, and volatilities depend only on $c^{b}$, and assume throughout that such an equilibrium exists.

The market price is of the form $P_{t}=\zeta\left(c_{t}^{b}\right) C_{t}$, where the price-dividend ratio $\zeta(\cdot)$ is a function that we need to determine as the solution to a differential equation. We provide the details of the analysis in the appendix, and collect the main results in the following proposition, including the differential equation for $\zeta$. To state the proposition, we use the representative agent's risk aversion $\gamma_{t}$ and agent $b$ 's relative importance $x_{t}$ given above in (12)-(13), as well as the additional definitions

$$
\begin{aligned}
& \bar{\kappa}=\gamma \sigma^{C} \\
& \bar{\sigma}=\sigma^{C}+\frac{\zeta^{\prime} c^{b}}{\zeta}\left(\bar{\kappa}-\sigma^{C}\right) .
\end{aligned}
$$

As is clear from the proposition, $\bar{\kappa}$ is the market Sharpe ratio without margin constraints and $\bar{\sigma}$ is the return volatility without margin constraints for the same values of $c^{b}$ and $\zeta(\cdot){ }^{7}$

Proposition 6 (Calculating Equilibrium) The margin constraint binds if and only if $\frac{\bar{\kappa}}{\bar{\sigma}}>\frac{1}{m}$ or, equivalently, if and only if $\frac{\kappa}{\sigma}>\frac{1}{m}$. The market Sharpe ratio, $\kappa \equiv \frac{\mu-r^{c}}{\sigma}$, and the return volatility, $\sigma$, are given by

$$
\begin{aligned}
\kappa & =\bar{\kappa}+\frac{x}{1-x} \frac{\bar{\sigma}}{1-\frac{\zeta^{\prime} c^{b}}{m \zeta}}\left(\frac{\bar{\kappa}}{\bar{\sigma}}-\frac{1}{m}\right)^{+} \\
\sigma & =\bar{\sigma}-\frac{\zeta^{\prime} c^{b}}{\zeta} \frac{\bar{\sigma}}{1-\frac{\zeta^{\prime} c^{b}}{m \zeta}}\left(\frac{\bar{\kappa}}{\bar{\sigma}}-\frac{1}{m}\right)^{+} .
\end{aligned}
$$

\footnotetext{
${ }^{7}$ Note, however, that in an economy without margins $c_{t}^{b}$ has a different distribution for given time-0 endowments and the function $\zeta$ is different.
} 
The optimal risky-asset allocation of the risk-tolerant agent $b$ is

$$
\theta^{b}=\frac{\bar{\kappa}}{\bar{\sigma}}-\left(\frac{\bar{\kappa}}{\bar{\sigma}}-\frac{1}{m}\right)^{+}
$$

and his shadow cost of capital, $\psi$, is

$$
\psi=\frac{\sigma^{2}}{m}\left(\frac{\kappa}{\sigma}-\frac{1}{m}\right)^{+} .
$$

Finally, the price-to-dividend ratio $\zeta\left(c^{b}\right)$ solves the ordinary differential equation

$$
\begin{aligned}
0= & 1+\zeta\left(\mu^{C}-r^{c}-\gamma^{a} \sigma^{C}\left(1-c^{b}\right)^{-1}\left(\sigma^{C}-c^{b} \sigma \theta^{b}\right)\right)+ \\
& \zeta^{\prime} c^{b}\left(r^{c}-\rho+\sigma \theta^{b} \kappa-\mu^{C}-\gamma^{a}\left(\sigma \theta^{b}-\sigma^{C}\right)\left(1-c^{b}\right)^{-1}\left(\sigma^{C}-c^{b} \sigma \theta^{b}\right)\right)+ \\
& \frac{1}{2} \zeta^{\prime \prime}\left(c^{b}\right)^{2}\left(\sigma \theta^{b}-\sigma^{C}\right)^{2} .
\end{aligned}
$$

This proposition offers a number of interesting insights in addition to illustrating the derivation of equilibrium. First, to understand when the margin constraint binds, consider the brave agent's optimal position without margin constraints: he wants to invest $\frac{\mu-r^{c}}{\sigma^{2}}=\frac{\kappa}{\sigma}$ in the risky asset, but, since he faces a margin of $m$, he can at most lever up to $\frac{1}{m}$. Hence, he is constrained if $\frac{\kappa}{\sigma}>\frac{1}{m}$. The margin constraint changes the equilibrium Sharpe ratio $\kappa$ and volatility $\sigma$, but, nevertheless, the states of nature with binding margin constraints can be determined simply by looking at whether the agent would be constrained when the Sharpe ratio $\bar{\kappa}$ and volatility $\bar{\sigma}$ are computed without margins (given the actual state $c^{b}$ and equilibrium valuation ratio $\zeta$ ), i.e., $\frac{\bar{\kappa}}{\bar{\sigma}}>\frac{1}{m}$.

Importantly, Equation (21) shows that, for a given value $c^{b}$, the market Sharpe ratio $\kappa$ is higher when the constraint binds. This is intuitive because the constraint prevents the optimal sharing of risk, meaning that the risk-averse agent $a$ has to be induced, via a higher reward for risk, to take on more risk than he would absent constraints.

Equation (22), on the other hand, suggests that the volatility decreases with the introduction of constraints, as long as the price-to-dividend ratio increases with the importance of agent $b .^{8}$ The explanation of the result lies in the fact that, when the constraint binds, agent $b$ takes less risk than he would otherwise, which makes $c^{b}$, and consequently the P/D ratio $\zeta$, less volatile.

Finally, (24) gives the shadow cost of capital, $\psi$. On one hand, this shadow cost depends on the distance $\left(\frac{\kappa}{\sigma}-\frac{1}{m}\right)^{+}$between the unconstrained and the constrained optima, which increases with the severity $m$ of the margin constraint. On the other hand, a higher $m$ means that each dollar can be leveraged less, reducing the shadow cost of capital. The overall effect of $m$ on $\psi$ is non-monotonic.

In our calibration, we solve for the function $\zeta$ numerically, using as boundary conditions the price-to-dividend ratios that obtain in one-agent models with $c^{b}=0$ and $c^{b}=1$. Once the

\footnotetext{
${ }^{8}$ Since agent $b$ is the less risk averse, this property is intuitively appealing, but does not obtain generally because of the non-monotonic effect of aggregate risk aversion (in a CRRA world) on the interest rate.
} 
equilibrium price dynamics for the market and the collateralized-loan rate are thus computed, we calculate the value of the Lagrange multiplier $\psi$ from (24) and the uncollateralized interest rate $r^{u}$ then follows immediately from Proposition $1, r^{u}=r^{c}+\psi$. The price of a derivative $i^{\prime}, P_{t}^{i^{\prime}}=\zeta^{i^{\prime}}\left(c_{t}^{b}\right) C_{t}$, is calculated by solving a linear ODE for its price-dividend ratio $\zeta^{i^{\prime}}$ :

Proposition 7 The price-to-dividend ratio $\zeta^{i^{\prime}}\left(c^{b}\right)$ for derivative $i^{\prime}$ solves the differential equation

$$
\begin{aligned}
0= & 1+\zeta^{i^{\prime}}\left(\mu^{C}-r^{c}-\sigma \theta^{b} \sigma^{C}-\frac{m^{i^{\prime}}}{m}\left(\mu-r^{c}-\sigma \theta^{b} \sigma\right)\right) \\
& +\zeta^{i^{\prime \prime}} c^{b}\left(r^{c}-\rho+\sigma \theta^{b} \kappa-\mu^{C}-\sigma \theta^{b}\left(\sigma \theta^{b}-\sigma^{C}\right)\right)+\frac{1}{2} \zeta^{i^{\prime \prime \prime}}\left(c^{b}\right)^{2}\left(\sigma \theta^{b}-\sigma^{C}\right)^{2} .
\end{aligned}
$$

While the general case can only be solved numerically, explicit expressions for the prices of the underlying assets and agent $b$ 's shadow cost of capital $\psi$ are available in a particular limit case.

Proposition 8 (Limit Prices and Shadow Cost of Capital) In the limit as the relative wealth of agent $b$ approaches 0 , the price of underlying asset $i$ approaches

$$
P^{i}=\frac{C_{t}}{\rho+\left(\gamma^{a}-1\right) \mu^{C}-\frac{1}{2} \gamma^{a}\left(\gamma^{a}-1\right)\left(\sigma^{C}\right)^{2}} .
$$

and agent b's shadow cost of capital approaches

$$
\psi=\frac{\left(\sigma^{C}\right)^{2}}{m}\left(\gamma^{a}-\frac{1}{m}\right)^{+} .
$$

We can further characterize the basis in the limit:

Proposition 9 (Limit Basis) In the limit as the relative wealth of agent $b$ approaches 0 , the required return spread between the underlying security $i$ and a derivative $i^{\prime}$ approaches

$$
\mu^{i}-\mu^{i^{\prime}}=\psi\left(m^{i}-m^{i^{\prime}}\right)
$$

if agent $b$ is long both securities, and

$$
\left|\mu^{i}-\mu^{i^{\prime}}\right|=\psi\left(m^{i}+m^{i^{\prime}}\right)
$$

if he is long/short the underlying and the derivative.

This proposition provides a natural benchmark for the basis, namely a product of the shadow cost of capital — which is common for all basis trades - and the margin use, which is either the difference or the sum of margins. In the real world, pairs of underlying and derivative securities with large margins $m^{i}+m^{i^{\prime}}$ also tend to have large margin spreads $m^{i}-m^{i^{\prime}}$, so testing the proposition does not rely heavily on knowing whether (29) or (30) applies. In the empirical section, we compare the basis per margin use for investment grade CDS-bond basis with the high-yield CDS-bond basis, relying on the prediction

$$
\frac{\mu^{i}-\mu^{i^{\prime}}}{m^{i}-m^{i^{\prime}}}=\frac{\mu^{j}-\mu^{j^{\prime}}}{m^{j}-m^{j^{\prime}}} .
$$




\begin{tabular}{ccccccc}
\hline$\mu^{C}$ & $\sigma^{C}$ & $\gamma^{a}$ & $\rho$ & $m$ & $m^{\text {medium }}$ & $m^{\text {low }}$ \\
\hline 0.03 & 0.08 & 8 & 0.02 & 0.4 & 0.3 & 0.1 \\
\hline
\end{tabular}

Table 1: Parameters used in calibration

\subsection{Calibration}

We present here a set of quantitative results based on the solution of the model described above and the parameters in Table 1. An advantage of our model is that all the parameters are easy to relate to real-world quantities so the interpretation of our assumptions and results is clear.

The aggregate-consumption mean growth $\mu^{C}$ and its volatility $\sigma^{C}$ are chosen between those of actual consumption growth and those of actual dividend growth, since the literature uses these benchmarks. The risk aversion $\gamma^{a}=8$ of agent $a$ is chosen at the high end of what the literature typically views as the "reasonable" range between 1 and 10, since agent $a$ is the more risk averse agent, and the discount rate $\rho$ is also at a conventional level. The margin of each underlying asset $m$ is $40 \%$, and we consider a low-margin derivative with margin $m^{\text {low }}=10 \%$, a medium-margin derivative with $m^{\text {medium }}=30 \%$, and a derivative with a margin that varies randomly between $10 \%$ and $30 \%$ depending on the state of the economy as described below.

Figures 1-4 show different key properties of the model as functions of the economy's state variable, namely the proportion of consumption accruing to agent $b$. Since agent $b$ is less risk averse, he is more heavily invested in the risky asset and therefore loses more following a series of bad shocks. Thus, the states in which $c^{b}$ is small are states with "bad" fundamentals.

It is apparent in all three figures that the margin constraint binds if and only if $c^{b}$ is low enough, more precisely when $c^{b}$ is lower than 0.22 . The property is natural: when agent $b$ is poor his margin constraint is more binding and his shadow cost of capital is larger. This is because agent $a$ becomes a larger part of the market, which increases the market price of risk, and therefore increases the desired leverage of agent $b$.

Figure 1 shows three interest rates: the interest rate obtaining in the absence of constraints, and the collateralized and uncollateralized rates obtaining with constraints. As is seen in the figure, the collateralized interest rate (solid line) can be substantially lower than the complete-market rate in the bad states, while the uncollateralized rate can be extremely high, indicating the high value of capital to agent $b$. The difference between these rates is the shadow cost of capital, which can get close to $10 \%$ as in the data that we present in the next section.

Figure 2 plots the return spreads between the underlying security and two derivatives. The derivatives are distinguished by their different margin requirements: one has an intermediate margin requirement $m^{\text {medium }}=30 \%$ - lower than the margin requirement of the underlying asset, $m=40 \%$, but not as low as the margin requirement on the other derivative, which is $m^{\text {low }}=10 \%$. We see that the required return spread (or basis) can be up 
to $1 \%$ and $3 \%$, respectively, for the two derivatives, a similar magnitude to the empirically observed bases, and vary depending on the severity of the crisis as captured by a low $c^{b}$.

As predicted by the limit result (29), which can be viewed as an approximation, the return spread is roughly three times higher for the low-margin derivative than for the intermediatemargin derivative due to its three times larger margin spread, $\left(m-m^{l o w}\right) /\left(m-m^{\text {medium }}\right)=3$.

Another interesting feature of this figure is that the return spread is significantly above zero even in states where the constraint does not bind $\left(c^{b}>0.22\right)$. The explanation for this outcome lies with the securities' different betas. Indeed, low-margin securities have

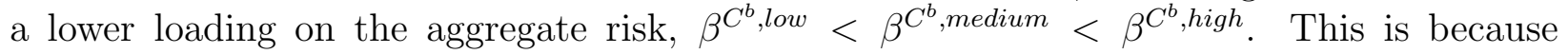
negative fundamental shocks lead to tightening of margin requirements, thus increasing the margin-based return premium, which leads to larger price drops for high-margin securities. It is noteworthy that this phenomenon amplifies the return spread and kicks in even before margin constraints bind.

Similarly, lower-margin securities have lower volatilities ${ }^{9}$ because they are less exposed to changes in the shadow cost of capital, i.e., they have less liquidity risk. The ratio of the risk (beta or volatility) of low-margin securities to high-margin securities is U-shaped. When constraints are far from binding (large $c^{b}$ ), margins have little effect on returns, and the risks of high- and low-margin securities are similar. For lower values of $c^{b}$ where constraints become binding, the risk difference becomes significant, but it eventually goes down as $b$ agents are wiped out $\left(c^{b}\right.$ close to zero).

In addition, the dependence of the sensitivity to aggregate risk on the margin size also implies that, once the idiosyncratic components $s^{i}$ are taken into account, the returns on low-margin securities are less highly correlated than those on high-margin securities, all else equal. Furthermore, the bases between underlying-derivative pairs, driven largely by the common shadow cost of capital, are more correlated with each other than the underlying securities are.

Figure 3 plots the Sharpe Ratios (SR) of the underlying in an alternative economy with no margin constraints, the underlying when there exist margin constraints, and of the two derivatives. We see that the Sharpe ratio of the underlying is higher with the constraint than without it to compensate for the cost of margin use. The SR of the derivatives is lower than that of the underlying due to their lower margins.

Finally, Figure 4 shows the price premium of derivatives above the price of the underlying, $P^{\text {derivative }} / P^{\text {high }}-1$. We consider this quantity both for the low- and medium-margin derivatives, as well as for a varying-margin derivative. The margin of the latter is $10 \%$ in "good states," where $c^{b} \geq 0.15$, and increases to $30 \%$ in "bad states", where $c^{b}<0.15$. The price premia can be very large, especially for low-margin securities in bad states of the economy. Interestingly, the price premia are significant even when the margin constraints are not binding or even close to being binding. This is because the price reflects the possibility of future binding margin constraints, and puts a premium on securities with low margins

\footnotetext{
${ }^{9}$ In various calibrations, we found that higher-margin securities have larger betas and volatilities. We can show this result in general using Malliavin-calculus techniques, provided that the ratio $\psi / c^{b}$ decreases with $c^{b}$. While this ratio clearly decreases at both $c^{b}=0$ and $c^{b}=\sup \{c \mid \psi(c)>0\}$, i.e., where the constraint just binds, we could not prove that it does everywhere.
} 
in such states of nature. Since the random-margin security has a high margin in the worst states, it is priced similarly to the high-margin security even when its margin is low.

Another way of looking at the price level is to consider how the price-dividend ratio depends on the state of the economy $c^{b}$. Our calibration yields the natural outcome, also discussed above in footnote 8 , that the price-dividend ratio $\zeta$ is increasing in $c^{b}$, i.e., higher valuation ratios obtain in good times. (We omit the graph for brevity.) Conversely, the dividend yield (the reciprocal of the price-dividend ratio) is lower in good times. In the empirical Section 3.1 below we show that the dividend yield in the stock market is linked to the CDS-bond basis, consistent with both depending on how constrained the economy is.

\section{Empirical Applications}

This section applies our model to the CDS-bond basis, the failure of the covered-interest rate parity, the pricing of the Fed's lending facilities, and to quantify the cost of capital requirements.

\subsection{The CDS-Bond Basis}

The CDS-bond basis is a measure of the price discrepancy between securities with nearly identical economic exposures, namely corporate bonds and credit default swaps (CDS). Said simply, the CDS-bond basis is what one can earn by buying a corporate bond and a CDS that protects against default on the bond. ${ }^{10}$ Since this package in principle has no risk if one can hold to maturity (though there are certain risks in the real world), the basis reflects a deviation from the Law of One Price. However, to earn an arbitrage profit one must use capital, and during a funding crisis capital is required to earn excess returns for constrained investors, so this is consistent with our margin-based asset pricing.

Another way of stating the apparent puzzle is to note that the yield spread on a corporate bond is higher than the CDS spread. According to our model, this is because agents can get credit exposure with less use of margin capital through CDS and, therefore, they are willing to earn a smaller expected return per notional, but a similar return per use of margin capital.

To understand the difference in margin requirements of corporate bonds and CDS, consider a hedge fund that buys a corporate bond. It must naturally use capital to pay the bond's price. The hedge fund can borrow using the bond as collateral, but this uses the hedge fund's broker's balance sheet. In light of our model, all capital use by risk-tolerant agents is costly, so the question is whether the broker can in turn borrow against the bond from an unconstrained agent such a cash-rich commercial bank. This can be done only to a limited extent if the commercial bank does not have experience trading such bonds, since corporate bonds are illiquid, making the evaluation of their value and risk potentially dif-

\footnotetext{
${ }^{10}$ Sometimes the CDS-bond basis is reported with the opposite sign. For simplicity, we use a convention that implies a positive basis during the crisis that started in 2007 .
} 
ficult. Importantly, the bond's market illiquidity also means that it can be difficult, time consuming, and costly to sell the bond during times of stress.

A CDS, on the other hand, is a derivative with zero present value so it does not inherently use capital. A hedge fund entering into a CDS must nevertheless post margin to limit the counterparty risk of the contract. Since the CDS margin mostly reflects the economic counterparty risk, whereas the corporate-bond margin additionally reflects its inherent cash usage and market illiquidity, the corporate-bond margin is larger than the CDS margin. In short, margins on "funded" underlying assets such as corporate bonds are larger than those of "unfunded" derivatives.

We test the model's predictions for (i) the time-series of the deviation from the Law of One Price (LoOP); (ii) the cross-section of the LoOP deviations for different pairs of CDS/bond; and (iii) the time-series and cross-section of the risk (measured as volatility and beta) of the CDS's and bonds. We first describe the data.

\section{Data}

We use data on the returns of the CDX index and S\&P500 from Bloomberg, the Merrill Lynch intermediate corporate return indices in excess of the same-maturity swaps from Merrill Lynch, the CDS-bond basis from a major broker-dealer, LIBOR and GC-repo rates from Bloomberg, and the average dividend yield of U.S. stocks from MSCI. Further, we use the Federal Reserve Board's survey, "Senior Loan Officer Opinion Survey on Bank Lending Practices," focusing on the net percent of respondents tightening their credit standards.

\section{Testing the Model's Time-Series LoOP Predictions}

To consider our model's time-series predictions, Figure 5 shows the average CDS-bond basis for high-grade bonds, the spread between the 3-month uncollateralized LIBOR loans and 3-month general collateral (GC) repo rate, and the Fed's survey measure of tightening credit standards.

We see that tighter credit standards (possibly reflecting more binding margin constraints) are associated with higher interest-rate spreads and a widening of the basis, consistent with our model's predictions. The link between the interest-rate spread and the basis, in particular, is related to Propositions 4 and 9 that describe the dependence of the basis on the shadow cost of capital and Proposition 1 linking the cost of capital to the interest-rate spread.

We test these predictions more formally in Table 2. In particular, Panel A reports time-series regressions of the CDS-bond basis on, respectively, the TED spread, the credit standards, and the average dividend yield of U.S. stocks. The dividend yield is the dividend of stocks, divided by their price, and it can be viewed as a measure of required returns. Specifically, in our calibration in Section 2.2, a high dividend is associated with a poor state of the economy where constraints are binding and deviations of the LoOP occur. We include the dividend yield to address an additional prediction of the model, namely that the funding frictions affect required returns broadly, including in the stock markets. 
We run these univariate regression both for the average basis among investment-grade (IG) securities and among high-yield (HY) securities. We see that both the IG and HY bases load significantly on the first two measures of funding illiquidity as well as on the dividend yield, as predicted by the model. The credit standard has an $R^{2}$ as high as $75 \%$ for IG and $67 \%$ for HY, and the dividend yield has the highest $R^{2}$, in excess of $80 \%$ for both IG and HY. While consistent with the model, it is surprising that the deviations from the Law of One Price in the credit markets appear so closely linked not only to the funding markets, but even to the stock market.

While these results formalize the connection between the bases and the funding measures that is visually clear in Figure 5, there can be severe biases in connection with regressions of persistence variables such as these. Running the regression in changes has better smallsample properties as changes are more stationary and, effectively, the sample has more independent observations. Panel B of Table 2 reports the regressions in changes. To account for the potential bias due to non-synchronous trading (i.e., stale prices) in the monthly regression of changes, ${ }^{11}$ we include a lagged value of the explanatory variable (following Dimson (1979) and many others),

$$
\text { basis }_{t}=\alpha+\beta_{1} x_{t}+\beta_{2} x_{t-1}+\varepsilon_{t} .
$$

We then report the biased-adjusted slope coefficient $\beta_{1}+\beta_{2}$ and its t-statistic, estimated using the asymptotic variance-covariance matrix of $\left(\beta_{1}, \beta_{2}\right)$. We see that the coefficients remain highly significant for all the explanatory variables and for both the IG and HY bases. The changes of the explanatory variables continue to have a high degree of explanatory power with $R^{2}$ 's ranging from $23 \%$ to $47 \%$.

The model's prediction regarding the relation between the magnitude of the interestrate spread and the magnitude of the basis is rejected in the data, if LIBOR is the true uncollateralized interest rate. Proposition 9 predicts that the basis is the shadow cost of capital multiplied by a number less than 1, and Proposition 1 that the shadow cost of capital is equal to the interest-rate spread. However, the basis is in fact higher than the interest-rate spread at the end of the sample. This happens, most likely, because the financial institutions' shadow cost of capital is larger than the LIBOR spread, for a couple of reasons: the Fed keeps the LIBOR down (see next section), many arbitrageurs (e.g., hedge funds) cannot borrow at LIBOR, and even those that can borrow at LIBOR cannot use a LIBOR loan to increase their trading, as they must limit their leverage.

\section{Testing the Model's Cross-Sectional LoOP Predictions}

We next test the model's cross-sectional predictions for the deviation from the LoOP. For this, we compare the basis of investment-grade (IG) bonds with that of high-yield (HY) bonds as seen in Figure 6. To facilitate the comparison in light of our model, we adjust the bases for their relative margin spreads. Since IG corporate bonds have a margin around

\footnotetext{
${ }^{11} \mathrm{As}$ is standard, we do not add a lagged variable in regressions in levels since this introduces co-linearity problems and non-synchronous trading has little effect on the regression in levels.
} 
$25 \%$ and IG CDS have margins around 5\%, the IG margin differential is $20 \%$. Hence, the adjusted IG basis is basis/0.20. Similarly, we estimate that the HY margin differential is around $50 \%$ so the HY adjusted basis is basis/0.50. These margin rates are based on a broker's estimates and the estimate is subject to a substantial amount of uncertainty since margins are opaque and vary between brokers and clients and over time. Propositions 4 and 9 predict that the bases adjusted for margin in this way should line up in the cross section so that the expected profit per margin use is constant in the cross section. Figure 6 shows that the adjusted bases track each other quite closely.

We test the statistical significance of this cross-sectional relation in Table 3. Panel A shows the regression of the HY basis on the IG basis, both in levels and changes. For the change regression, we adjust for non-synchronous prices as described above, and have the IG basis on the right-hand side as it is based on the more liquid instruments. We see that the close connection between IG and HY bases is highly statistically significant.

To further test the model's cross-sectional predictions, Panel B reports the following. First, we estimate the slope of the cross-sectional required return-margin curve at each point in time. Specifically, each month, we regress the two bases on the IG and HY margin differences $(0.2,0.5)$ :

$$
\text { basis }^{i}=\text { slope } \times\left(m^{i, \text { bond }}-m^{i, C D S}\right)+\varepsilon^{i} .
$$

This produces an estimate of the slope at each time, that is, the return compensation per unit of margin capital. (We get similar results if we include a constant term.) According to the model, this margin-return slope captures the shadow cost of capital $\psi$ (Propositions 4 and 9). Since the model also links $\psi$ to interest-rate spreads, credit tightness, and risk premia, we regress the estimated return-margin slope on such measures in Panel B. We see that all the variables are statistically significant in both levels and changes, and that their explanatory power is large.

\section{Testing the Model's Predictions for Liquidity Risk}

The model predicts that when margin constraints are not binding, securities with the similar fundamental risk should have similar volatilities and market betas, even if their margin requirements are different. In times of (near-)binding constraints, however, securities with high margin should have larger volatilities and betas as seen in Section 2.2. Indeed, high-margin securities have more funding-liquidity risk because their large use of capital makes them sensitive to changes in the tightness of capital constraints.

To test these model predictions on how margin requirements affect liquidity risk, Tables 4 and 5 consider the volatilities and market betas of CDSs and corporate bonds, both in the early sample before the crisis $(9 / 2005-6 / 2007)$, the crisis sample $(7 / 2007-12 / 2009)$, and the full sample. We estimate betas relative to the U.S. stock market as proxied by the S\&P500 index, and we use the returns of CDX index and the Merrill Lynch intermediate corporate return index in excess of the same-maturity swaps.

The model's predictions are born out in the data. Tables 4 and 5 show that CDS and bonds indeed have similar volatilities and betas in the pre-crisis sample. If anything, corpo- 
rate bonds have slightly lower volatilities and betas. During the crisis sample, however, the high-margin corporate bonds have much larger volatilities and betas than the low-margin CDS. We see that this pattern is consistent across investment-grade and high-yield securities. The volatilities are estimated with precision (the standard errors of these numbers are a few percentage points) and the difference between bonds and CDS is significant (not reported for brevity). The difference between the bond and CDS betas is tested in Panel B of Table 5, and we see that the difference is significant for IG securities.

\subsection{Effects of Monetary Policy and Lending Facilities}

The Federal Reserve has tried to alleviate the financial sector's funding crisis by instituting various lending facilities. These programs include the Term Auction Facility (TAF), the Term Securities Lending Facility (TSLF), the Term Asset-Backed Securities Loan Facility (TALF), and several other programs. ${ }^{12}$ The TAF was instituted in December 2007 in response to address the "pressures in short-term funding markets". With the TAF, the Fed auctions collateralized loans to depository institutions at favorable margin requirements with 28-day or 84-day maturity.

As the crisis escalated, the Fed announced on March 11, 2008 the TSLF, which offers Treasury collateral to primary dealers in exchange for other program-eligible collateral such as mortgage bonds and other investment grade securities for 28 days. Since this is an exchange of low-margin securities for higher-margin securities, it also improves the participating financial institutions' funding condition. By exchanging a mortgage bond for a Treasury and then borrowing against the Treasury, the dealer effectively has its margin on mortgage bonds reduced.

The Federal Reserve announced the additional creation of the TALF on November 25, 2008. The TALF issues non-recourse loans with term up to three years of eligible asset-backed securities (ABS) backed by such things as student loans, auto loans, credit card loans, and loans relating to business equipment. The TALF is offered to a wide set of borrowers, not just banks (but the borrowers must sign up with a primary dealer, which creates an additional layer of frictions).

These programs share the feature that the Fed offers lower margins than what is otherwise available in order to improve the funding of owners or buyers of various securities. This improves the funding condition of the financial sector and, importantly, makes the affected securities more attractive than they would be otherwise. Indeed, the goal of the TALF is to "help market participants meet the credit needs of households and small businesses by supporting the issuance of asset-backed securities." 13

In terms of our model, this can be understood as follows. The Fed offers a margin $m^{i, F e d}$ for security $i$, say a student-loan ABS, which is lower than the prevailing margin,

\footnotetext{
${ }^{12}$ We thank Adam Ashcraft, Tobias Adrian, and participants in the Liquidity Working Group at the NY Fed for helpful discussions on these programs.

${ }^{13}$ See http://www.newyorkfed.org/markets/talf_operations.html.
} 
$m^{F e d, i}<m^{i}$. This lowers the required return of a derivative security:

$$
E\left(r^{i, F e d}\right)-E\left(r^{i, n o F e d}\right)=\left(m^{F e d, i}-m^{i}\right) \psi<0 .
$$

Said differently, the Fed program increases the affected security's price (Proposition 5). Hence, this ABS can be issued at an increased price, which makes the market more viable since students can only pay a certain interest rate.

Ashcraft, Gârleanu, and Pedersen (2010) provide survey evidence from financial institutions to see how their bid prices for various securities depend on the financing that the Fed would offer. The surveyed bid price increases as the Fed reduces its offered margin, consistent with our model. For instance, the surveyed bid price of a super senior CMBS tranche with an expected life of 7 years with no Fed financing is $\$ 57$, but increases to $\$ 92.5$ with maturity matched financing with a low margin, a very large asset pricing effect. Similarly, the bid price of a tranche with 2.5 years of expected life increases from $\$ 84$ with no financing to $\$ 92$ with financing with a low margin. This corresponds roughly to an annualized decrease in expected return of $3.5 \%$.

Let us consider this number in the context of our model. If the shadow cost of capital is around $10 \%$ as implied by the IG and HY CDS-bond basis at the height of the liquidity crisis, and CMBS tranches are derivatives only held by the risk-tolerant investor, then Equation (33) implies an effect of $3.5 \%$ if the Fed improves the margin terms by 35 percentage points, so the model-implied effect is in the right neighborhood.

Ashcraft, Gârleanu, and Pedersen (2010) also provide evidence that the TALF lending facility had an impact on the market prices of CMBS bonds in a way that is consistent with our model.

\subsection{Failure of the Covered Interest-Rate Parity (CIP) and the Fed's Liquidity Swap Lines}

While textbooks on international finance acknowledge the failure of the uncovered interestrate parity, the so-called covered interest-rate parity (CIP) is often taken to hold by definition since arbitrage should enforce the Law of One Price. The covered interest rate parity says that if the local interest rate is $r$, the foreign interest rate is $r^{*}$, the spot exchange rate is $e$, and the forward exchange rate that can be locked in now is $f$, then $1+r=f / e\left(1+r^{*}\right)$. That is, putting the money in the local bank earns $1+r$ which should be the same as exchanging a dollar for $1 / e$ units of foreign currency, earning $1+r^{*}$ abroad, and guaranteeing to exchange the money back at the exchange rate of $f$ to get $f / e\left(1+r^{*}\right)$.

This parity has nevertheless failed due to supply and demand imbalances in the forward market and because it requires capital (margin) to trade to profit from deviations from parity. To understand the background of this surprising effect, recall first that the funding problems of financial institutions in the crisis of 2007-2009 quickly spread globally. Banks in many countries had funding problems both in their local currency and in US dollars, perhaps because many transactions are done in dollars.

To facilitate dollar funding for foreign banks, the Fed authorized temporary reciprocal currency arrangements called "central bank liquidity swap lines" on December 12, 2007 
(Coffey, Hrung, Nguyen, and Sarkar (2009)). Through these swap lines, the Fed lent dollars to foreign central banks who in turn lent these dollars to their local banks.

Despite this effort, parity has been violated as a clear sign that the currency arbitrageurs' margin requirements are binding as seen in Figure 7. The figure further shows that the time series pattern of the deviation tracks the TED spread (i.e., the spread between LIBOR and Treasury bills) in the 2007-2009 crisis and in liquidity crisis of 1998 (involving LTCM among other events). This co-movement is highly statistically significant both in levels and monthly changes (regressions are not shown for brevity).

\subsection{Quantifying the Cost of Capital Requirements: Incentives for Regulatory Arbitrage}

We can also use our model to quantify the shadow cost of Basel capital requirements in order to help understand the banks' incentives to perform "regulatory arbitrage" by moving assets off their balance sheet and tilting their portfolios towards AAA securities with low regulatory capital requirements.

For this, we note that the Basel requirement has a similar form to the margin requirement. It can loosely be captured by a similar equation to our model's margin requirement (see Brunnermeier and Pedersen (2009)):

$$
\sum_{i} m^{R e g, i}\left|\theta^{i}\right| \leq 1
$$

where $\theta^{i}$ is the fraction of wealth in security $i$ as before and $m^{R e g, i}$ is the regulatory capital requirement ( $8 \%$ times a risk weight under some rules).

When the prevailing margins are low, the regulatory requirement may be more binding than the funding-based margin requirement. In this case, the margin $m^{i}$ in our pricing formula is replaced by the regulatory requirement (34). Hence, a bank's required return increases in the regulatory capital requirement multiplied by the shadow cost of capital, $\psi m^{\text {Reg,i }}$. If the shadow cost of regulatory capital is $1 \%$ and a bank can move off balance sheet an asset with risk weight of $100 \%$, then its required return for that asset is reduced by $1 \% \times 8 \% \times 100 \%=80$ basis points.

\section{Conclusion}

We derive a tractable general-equilibrium asset-pricing model that accounts explicitly for the pricing of margins. The model captures several of the salient features of the recent and past liquidity crises: a negative fundamental shock leads to losses for leveraged agents, including the financial sector; these agents face funding problems as they hit margin constraints; the binding constraints lead to drops in Treasury rates and general-collateral interest rates, to spikes in interest-rate spreads, risk premia, and the pricing of margins, and to bases (or price gaps) between securities with identical cash flows but different margins. 
We illustrate the model through a calibration, test it empirically using the CDS-bond basis and the failure of the covered interest-rate parity, and show how the model-implied cost of capital requirements quantifies the banks' incentives to use off-balance sheet vehicles. Finally, we estimate the effect of the Fed's lending facilities, which is helpful in evaluating the unconventional monetary policy tools used during liquidity crises. 


\section{Appendix}

\section{A Linear and Non-Linear Margin Constraints}

We consider a non-linear margin requirement (7) that depends on the absolute value of the position $\left|\theta^{i}\right|$. Hence, both long $\left(\theta^{i}>0\right)$ and short $\left(\theta^{i}<0\right)$ positions make the constraint tighter, i.e., both long and short positions use capital. It is interesting to compare this to a linear constraint sometimes assumed in the literature:

$$
\sum_{i} m_{t}^{i} \theta^{i}+\eta^{u} \leq 1
$$

While such a linear constraint is simpler to handle mathematically, it precludes the bases that are central to our study:

Proposition 10 If agents face only linear margin requirements (A.1) and at least one derivative exists with $m^{i^{\prime}}<m^{i}$, then any equilibrium is as if there were no margin constraints at all and there can be no deviations from the Law of One Price in equilibrium, that is, the basis is always zero.

Proof of Proposition 10. For any asset allocations of the two agents, the linear margin constraint is slack "in the aggregate":

$$
W_{t}^{a} \sum_{j} m_{t}^{j} \theta_{t}^{j, a}+W_{t}^{b} \sum_{j} m_{t}^{j} \theta_{t}^{j, b}<W_{t}^{a}+W_{t}^{b} .
$$

This means that the linear margin constraint must be slack for at least one of the agents, who is therefore not constrained at time $t$.

Suppose now that on a non-zero-measure set there fails to exist a market-price-of-risk process, i.e., a process $\kappa$ taking values in $\mathbb{R}^{N}$ such that $\sigma_{t}^{j} \kappa_{t}=\mu_{t}^{j}-r_{t}^{c}$ for all securities $j$. Then one of the two agents can trade on a non-zero-measure set to make risk-less strictly positive (although bounded) profits - i.e., a zero-value portfolio $\eta$ exists whose volatility is zero and that has strictly positive drift. This contradicts the notion of equilibrium. Consequently, a market-price-of-risk process exists. It follows, under technical integrability conditions, that an equivalent martingale measure, defined by the stochastic exponential of this process, also exists, so that assets with identical cashflows have identical payoffs. (See Duffie (2001), Chapter 6, Section G.)

Finally, consider two securities, $i$ and $j$, with identical cashflows and prices but different margin constraints: $m_{t}^{i}>m_{t}^{j}$ on some set. If any agent is constrained when $m_{t}^{i}>m_{t}^{j}$, then she can relax her constraint by going long $n$ shares of asset $j$ and short $n$ shares of asset $i$ : the trade has no cash-flows implications and makes the constraint slack. For $n$ low enough, the other agent's margin constraints remains slack due to (A.2), and therefore both agents are unconstrained while their consumption processes remain the same. (Alternatively, we can note that the CAPM relationship $\mu_{t}^{i}-r_{t}^{c}=\beta^{g, j}+\psi_{t}^{g} m_{t}^{i}$ implies that $\psi_{t}^{g}=0$ for both agents $g \in\{a, b\}$.) 


\section{B Proofs}

Proof of Propositions 1 and 4. These proofs are in the body of the paper.

Rather than offering a proof to the special Proposition 2, we state and prove its general version. To this end, we define the risk-tolerance fraction due to agent $a$ by $\bar{x}_{t}=1-x_{t}$. We recall that $\psi$ is agent $b$ 's shadow cost of funding, and we denote $a$ 's shadow cost of funding by $\bar{\psi}$. Finally, $y^{i}$ indicates whether $b$ is long $\left(y_{t}^{i}=1\right)$, short $\left(y_{t}^{i}=-1\right)$, or has no position $\left(y_{t}^{i} \in[-1,1]\right)$ in an asset, and similarly $\bar{y}^{i}$ indicates the sign of $a$ 's position.

Proposition 2' (Margin CCAPM) The expected excess return $\mu_{t}^{i}-r_{t}^{c}$ on an underlying asset is given by the standard consumption CAPM adjusted for funding costs:

$$
\mu_{t}^{i}-r_{t}^{c}=\gamma_{t} \beta_{t}^{C, i}+\lambda_{t}^{m, i} m_{t}^{i},
$$

where the funding cost is the product of the margin requirement and the margin premium:

$$
\lambda_{t}^{m, i}=\bar{x}_{t} \bar{\psi}_{t} \bar{y}_{t}^{i}+x_{t} \psi_{t} y_{t}^{i}
$$

Proof of Proposition $2^{\prime}$. To understand the idea of the proof, suppose first that agent $a$ 's margin constraint never binds, so that he is (locally) unconstrained in his investment in the underlying assets. Consequently, deflating the gains process of any of these securities using his marginal utility process yields a local martingale. Specifically, agent a's marginal utility, which we denote by $\xi_{t}$, is given by

$$
\xi_{t}=e^{-\rho t}\left(C^{a}\right)^{-\gamma^{a}} .
$$

Further, we denote its drift and volatility by $\mu_{t}^{\xi}$ and $\sigma_{t}^{\xi}$ :

$$
d \xi_{t}=\xi_{t}\left(\mu_{t}^{\xi} d t+\sigma_{t}^{\xi} d w_{t}\right)
$$

and Ito's Lemma shows that

$$
\sigma^{\xi}=-\gamma^{a} \sigma^{C^{a}}
$$

The discounted value of the price and accumulated dividends,

$$
P_{t} \xi_{t}+\int_{0}^{t} C_{s} \xi_{s} d s,
$$

is a local martingale, so it has zero drift:

$$
0=\delta_{t}^{i}+P_{t}^{i} \mu_{t}^{\xi}+P_{t}^{i} \mu_{t}^{i}-\delta_{t}^{i}+P_{t}^{i} \sigma_{t}^{i}\left(\sigma_{t}^{\xi}\right)^{\top} .
$$

Since $\xi$ prices the risk-free collateralized lending, it holds that

$$
\mu_{t}^{\xi}=-r_{t}^{c} .
$$


Combining (B.5), (B.7), and (B.8) gives agent $a$ 's key pricing equation:

$$
\mu^{i}-r^{c}=\gamma^{a} \beta^{C^{a}, i} .
$$

Recall also agent $b$ 's pricing equation:

$$
\mu^{i}-r^{c}=\beta^{C^{b}, i}+y^{i} \psi m^{i} .
$$

Multiplying Equations (B.9) and (B.10) by $\left(\gamma^{a}\right)^{-1} C^{a}$, respectively $C^{b}$, and adding the results gives

$$
\left(\mu^{i}-r^{c}\right)\left(\frac{C^{a}}{\gamma^{a}}+C^{b}\right)=C \beta^{C, i}+C^{b} y^{i} \psi m^{i},
$$

which is equivalent to (14).

The general proof of this proposition involves characterizing the optimal portfolio choice of an arbitrary agent with utility function $u$ who faces convex portfolio constraints and redundant assets. The steps are the following:

Step 1. Construct a family of fictitious economies in which there are no redundant securities (derivatives) and where the drifts of asset prices and the (collateralized) interest rate are given, for $\nu \in \mathbb{R}^{N}$, by

$$
\begin{aligned}
\mu^{i, \nu} & =\mu^{i}+\nu^{i}+h(\nu) \\
r^{c, \nu} & =r^{c}+h(\nu),
\end{aligned}
$$

which are to be explained shortly. For ease of exposition, define also $\kappa^{\nu}=\sigma^{-1}\left(\mu+\nu-r^{c}\right)$ to be the market price of risk for the underlying securities in the fictitious market and let

$$
\nu^{i^{\prime}, \nu}=\sigma^{i^{\prime}} \kappa^{\nu}+r^{c}-\mu^{i^{\prime}}
$$

for all derivatives $i^{\prime}$. Defining $\mu^{i^{\prime}, \nu}$ analogously to $\mu^{i, \nu}$ would mean that there would be no arbitrage opportunity in the fictitious market even if the redundant securities were traded.

For any $\nu \in \mathbb{R}^{N}$, the function $h$ is defined as

$$
\begin{aligned}
h(\nu)= & \sup \left\{-\left(\sum_{i} \theta^{i} \nu^{i}+\sum_{i^{\prime}} \theta^{i^{\prime}} \nu^{i^{\prime}, \nu}\right) \mid \theta \in K\right\} \\
= & \sup \left\{-\left(\sum_{i} \theta^{i} \nu^{i}+\sum_{i^{\prime}} \theta^{i^{\prime}} \sigma^{i^{\prime}} \sigma^{-1} \nu\right)+\right. \\
& \left.\sum_{i^{\prime}} \theta^{i^{\prime}}\left(\left(\mu^{i^{\prime}}-r^{c}\right)-\sigma^{i^{\prime}} \kappa^{0}\right) \mid \theta \in K\right\} .
\end{aligned}
$$

The function $h(\nu)$ captures both the shadow value of capital and the increase to the interest rate that an agent would have to be offered in a world without redundant securities in order to achieve the same utility as when arbitrage opportunities are available to him. The first term in the last expression above represents the total additional return due to the higher 
drifts in the fictitious economy, while the second represents the arbitrage gains. Note that, since $K$ is bounded, $h$ takes finite values on $\mathbb{R}^{N}$.

The fictitious economies are constructed so that any consumption feasible in the original, constrained economy starting with a certain wealth is also feasible in each of these economies - because available returns are at least as high. By including all such economies, it also follows that there is one among them in which the optimal portfolio and consumption choices satisfy the original constraints.

Step 2. For any consumption plan, the trading strategy $\left\{\phi^{i}\right\}^{i}$ that attains it at the highest cost (initial wealth) among the optimal strategies in all fictitious economies is equivalent, in terms of risk exposure, to a strategy $\left(\left\{\theta^{i}\right\}^{i},\left\{\theta^{i^{\prime}}\right\}^{i^{\prime}}\right)$ that finances the consumption plan at the same cost and satisfies the constraints in the original economy. This is the new step relative to the literature.

To prove this statement, follow Cvitanić and Karatzas (1993) to define the maximum cost of (super-)replicating the consumption plan among all fictitious economies, from any time $\tau$ onwards:

$$
V_{\tau} \equiv \sup _{\nu} E^{\nu}\left[\int_{\tau}^{T} e^{-\int_{t}^{T} r_{s}^{c, \nu} d s} c_{t} d t\right]
$$

where $E^{\nu}$ is the equivalent martingale measure in the market defined by $\nu$, given by the state-price deflator $\xi^{\nu}$, which is defined by $\xi^{\nu}(0)=1$ and

$$
d \xi_{t}^{\nu}=-\xi_{t}^{\nu}\left(r^{c, \nu} d t+\left(\kappa^{\nu}\right)^{\top} d B_{t}\right)
$$

It follows that

$$
M_{t}^{\nu} \equiv V_{t} e^{\int_{0}^{t} r_{s}^{c, \nu} d s}
$$

is a supermartingale, so that it can be decomposed as

$$
M_{t}^{\nu}=V_{0}+\int_{0}^{t} \phi_{s}^{\nu} d w_{s}^{\nu}-B_{t}^{\nu}
$$

with $B_{t}^{\nu}$ an increasing process and $w^{\nu}$ a Brownian motion. Comparing $M^{\nu}$ with $M^{0}$ identifies $\phi^{\nu}$ as being independent of $\nu$ - let's denote it by $\phi$ - and it also implies

$$
\int_{0}^{t} e^{\int_{0}^{s} r_{v}^{c, \nu} d v} d B_{s}^{\nu}-\int_{0}^{t} e^{\int_{0}^{s} r_{v}^{c, \nu} d v} V_{s}\left(h\left(\nu_{s}\right)+\nu_{s}^{\top} \phi\right) d s=\int_{0}^{t} e^{\int_{0}^{s} r_{v}^{c} d v} d B_{s}^{0}
$$

We claim that, since the right-hand side of (B.12) is increasing, $\phi$ is equivalent to a strategy $\theta \in K$. Indeed, suppose that this is not the case. The strategies in the original market that are risk-equivalent to $\phi$ are $\theta=(\hat{\theta}, \tilde{\theta})$ such that

$$
\phi=\hat{\theta}+\left(\sigma^{-1}\right)^{\top} \tilde{\sigma}^{\top} \tilde{\theta}
$$


where $\tilde{\sigma}$ is the matrix of volatility vectors of the redundant securities. If the affine space $\Theta^{\phi}$ consisting of all such $\theta$ does not intersect the compact convex set $K$, then it is separated from it by a hyperplane, i.e., there exist a vector $v$ and $\epsilon>0$ such that

$$
v^{\top} \theta-v^{\top} \theta^{K} \geq \epsilon
$$

for all $\theta \in \Theta^{\phi}$ and $\theta^{K} \in K$. Note that $v$ is orthogonal to $\Theta^{\phi}$, i.e., $v^{\top}\left(\theta_{1}-\theta_{2}\right)=0$ for all $\theta^{1}, \theta^{2} \in \Theta^{\phi}$. In fact, $v^{\top} \theta=v^{\top}(\phi, 0)$ on $\Theta^{\phi}$, and $v^{\top}$ is a linear combination of the rows of $\left(I_{N},\left(\sigma^{-1}\right)^{\top} \tilde{\sigma}^{\top}\right)$ :

$$
v^{\top}=\hat{v}^{\top}\left(I_{N},\left(\sigma^{-1}\right)^{\top} \tilde{\sigma}^{\top}\right)
$$

for some $\hat{v} \in \mathbb{R}^{N}$.

Note now that

$$
h(\nu)=\sup \left\{-\nu^{\top}\left(\hat{\theta}+\left(\sigma^{-1}\right)^{\top} \tilde{\sigma}^{\top} \tilde{\theta}\right)+\sum_{i^{\prime}} \theta^{i^{\prime}}\left(\left(\sigma^{i^{\prime}}\right)^{\top} \kappa^{0}-\left(\mu^{i^{\prime}}-r^{c}\right)\right) \mid(\hat{\theta}, \tilde{\theta}) \in K\right\} .
$$

Let $\nu=R \hat{v}$ for some (large) scalar $R$ and note also that

$$
\begin{aligned}
h(\nu)+\nu^{\top} \phi \geq & \sup \left\{-\nu^{\top}\left(\hat{\theta}+\left(\sigma^{-1}\right)^{\top} \tilde{\sigma}^{\top} \tilde{\theta}\right) \mid(\hat{\theta}, \tilde{\theta}) \in K\right\}+\nu^{\top} \phi+ \\
& \sup \left\{\sum_{i^{\prime}} \theta^{i^{\prime}}\left(\left(\mu^{i^{\prime}}-r^{c}\right)-\sigma^{i^{\prime}} \kappa^{0}\right) \mid(\hat{\theta}, \tilde{\theta}) \in K\right\} \\
\geq & \sup \left\{-R \hat{v}^{\top}\left(I,\left(\sigma^{-1}\right)^{\top} \tilde{\sigma}^{\top}\right) \theta \mid \theta \in K\right\}+R v^{\top}(\phi, 0)+D \\
\geq & R \epsilon+D,
\end{aligned}
$$

where $|D|<\infty$ because $K$ is bounded.

Thus, if $\Theta^{\phi} \cap K=\emptyset, h(\nu)+\nu^{\top} \phi$ can be made arbitrarily large, and consequently, the left-, and therefore right-hand, side of (B.12) can be made decreasing, which would be a contradiction.

Step 3. The optimal consumption in the original economy is therefore optimal in one of the fictitious, unconstrained economies. Consequently, the marginal utility of the agent is proportional to $\xi^{\nu}$, giving

$$
\frac{u^{\prime \prime}\left(C^{g}\right)}{u^{\prime}\left(C^{g}\right)} C^{g} \sigma^{C^{g}}=\sigma^{-1}\left(\mu-r^{c}+\nu\right),
$$

or

$$
\mu^{i}-r^{c}=\gamma \beta^{C^{g}, i}-\nu^{i}
$$

Step 4. For $\nu$ that defines the constrained optimum, the optimal $\theta$ attains the supremum in the definition of $h(\nu)$. The characterization of $\nu$ then comes down to a simple linear optimization over a convex set. 
Suppose, for instance, that $\theta^{1}>0$, which implies $\nu^{1} \leq 0$, and let $\psi=-\frac{\nu^{1}}{m^{1}} \cdot{ }^{14}$ If $\theta^{2}>0$ and, say, $\frac{\nu^{2}}{m^{2}}>-\psi$, decreasing $\theta^{2}$ by $m^{1} \epsilon$ and increasing $\theta^{1}$ by $m^{2} \epsilon$ preserves the constraints but increases the objective by $\left(\frac{\nu^{2}}{m^{2}}+\psi\right) m^{1} \epsilon>0$. Thus $\frac{\nu^{i}}{m^{i}}=-\psi$ whenever $\theta^{i}>0$, so that (B.13) becomes

$$
\mu^{i}-r^{c}=\gamma \beta^{C^{g}, i}+\psi m^{i} .
$$

All other cases are treated similarly. Note also that $h(\nu)=\psi$.

As for the derivatives, from the definition of $\nu^{i^{\prime}}$ we have the relationship

$$
\begin{aligned}
\mu^{i^{\prime}}-r^{c} & =\sigma^{i^{\prime}} \sigma^{-1}\left(\mu+\nu-r^{c}\right)-\nu^{i^{\prime}} \\
& =\gamma \beta^{C^{g}, i^{\prime}}-\nu^{i^{\prime}} .
\end{aligned}
$$

Therefore the treatment of the derivative is the same as that of any underlying asset as long as the derivative position is not bound by a different constraint, which is entirely natural. If the derivative positions are constrained by other constraints, then the form of the "shadow returns' $\nu^{i^{\prime}}$ is different.

The next result is the general form of Proposition 3.

Proposition $3^{\prime}$ [Margin CAPM] The expected excess return $\mu_{t}^{i}-r_{t}^{c}$ on an underlying asset is given by the standard CAPM adjusted for funding costs based on the margins $m_{t}^{i}$ :

$$
\mu_{t}^{i}-r_{t}^{c}=\lambda_{t}^{\beta} \beta_{t}^{i}+\lambda_{t}^{m, i} m_{t}^{i}
$$

where $\lambda_{t}^{\beta}=\mu_{t}^{q}-r_{t}^{c}-\sum_{j} q_{t}^{j} \lambda_{t}^{m, j} m_{t}^{j}$ is a covariance risk premium and the margin premium $\lambda^{m, i}$ is defined in Proposition $\mathscr{2}^{\prime}$.

Proof of Proposition $\mathbf{3}^{\prime}$ The definition of the portfolio $q$ implies that

$$
\frac{d C_{t}}{C_{t}}=Q_{t} \frac{d P_{t}^{q}}{P_{t}^{q}}+d z_{t}
$$

for some process $Q$ and Brownian motion $z$ with $\operatorname{cov}_{t}\left(d P^{i}, d z\right)=0$ for all $i$. Proposition 2 therefore implies that

$$
\mu_{t}^{i}-r_{t}^{c}-\lambda_{t}^{m, i} m_{t}^{i}=Q_{t} \operatorname{cov}_{t}\left(\frac{d P_{t}^{q}}{P_{t}^{q}}, \frac{d P_{t}^{i}}{P_{t}^{i}}\right)
$$

Multiplying this equation by $q_{t}^{i}$ and summing over all $i$ yields

$$
\mu_{t}^{q}-r_{t}^{c}-\sum_{i} q_{t}^{i} \lambda_{t}^{m, i} m_{t}^{i}=Q_{t} \operatorname{var}_{t}\left(\frac{d P_{t}^{q}}{P_{t}^{q}}\right) .
$$

\footnotetext{
${ }^{14}$ Remember $K=\left\{\theta\left|\sum_{i}\right| \theta^{i} \mid m^{i} \leq 1\right\}$.
} 
Equations (B.16) and (B.17) immediately give the proposition.

Proof of Proposition 5. Write the agent's objective as

$$
\mathrm{E} \int_{t}^{\infty} e^{-\rho s}\left(u\left(C_{s}^{g}\right)-\lambda_{s}\left(\sum_{j}\left|W_{s} \theta_{s}^{j}\right| m_{s}^{j}+W_{s} \eta_{s}^{u}-W_{s}\right)\right) d s,
$$

where $\lambda$ is a Lagrange multiplier. (In the case of agent $b$, the HJB equation shows $\lambda$ to equal $(\rho W)^{-1} \psi$.) The agent acts as if unconstrained, provided that $\lambda$ is chosen appropriately.

Suppose that the agent invests in $\epsilon$ more shares of asset $i$, borrowing at the collateralized rate to do so. The agent adjusts consumption to absorb both the dividends and interest expense. Note that the only terms entering the constraint affected by this deviation are $\left|W_{s} \theta_{s}^{i}\right|$ and $W_{s}$. Letting $\epsilon$ tend to zero, the gain in utility is proportional to

$$
\begin{aligned}
& \operatorname{sign}(\epsilon) \mathrm{E}_{t} \int_{t}^{\infty} e^{-\rho s}\left(u^{\prime}\left(C_{s}^{g}\right)\left(\delta_{s}^{i}-r_{s}^{c} P_{t}^{i}\right)-\lambda_{s}\left(\tilde{y}_{s} P_{s}^{i} m_{s}^{i}-\left(P_{s}^{i}-P_{t}^{i}\right)\right)\right) d s \\
& \quad=\operatorname{sign}(\epsilon) \mathrm{E}_{t} \int_{t}^{\infty} e^{-\rho s}\left(u^{\prime}\left(C_{s}^{g}\right)\left(\delta_{s}^{i}-r_{s}^{c} P_{t}^{i}\right)-\lambda_{s} P_{t}^{i}+P_{s}^{i} \lambda_{s}\left(1-\tilde{y}_{s} m_{s}^{i}\right)\right) d s,
\end{aligned}
$$

where $\tilde{y}_{s}=1$ if $\theta_{s}^{i}>0, \tilde{y}_{s}=-1$ if $\theta_{s}^{i}<0$, and $\tilde{y}_{s}=\operatorname{sign}(\epsilon)$ if $\theta^{i}=0$. Since the deviation must (weakly) reduce utility regardless of the sign of $\epsilon$, it follows that

$$
P_{t}^{i} \mathrm{E}_{t} \int_{t}^{\infty} e^{-\rho s}\left(u^{\prime}\left(C_{s}^{g}\right) r_{s}^{c}+\lambda_{s}\right) d s=\mathrm{E}_{t} \int_{t}^{\infty} e^{-\rho s}\left(u^{\prime}\left(C_{s}^{g}\right) \delta_{s}^{i}+P_{s}^{i} \lambda_{s}\left(1-y_{s} m_{s}^{i}\right)\right) d s,
$$

where $y_{s}=1$ if $\theta_{s}^{i}>0, y_{s}=-1$ if $\theta_{s}^{i}<0$, and $y_{s} \in[-1,1]$ if $\theta_{s}^{i}=0$. Equation (B.18) implies

$$
P_{t}^{i} \mathrm{E}_{t} \int_{t}^{\infty} e^{-\rho(s-t)}\left(u^{\prime}\left(C_{s}^{g}\right) r_{s}^{c}+\lambda_{s}\right) d s=\mathrm{E}_{t} \int_{t}^{\infty} e^{-\rho(s-t)+\int_{t}^{s} e^{-\rho v} \lambda_{v}\left(1-y_{v} m_{v}^{i}\right) d v} u^{\prime}\left(C_{s}^{g}\right) \delta_{s}^{i} d s .
$$

Alternatively, $u^{\prime}\left(C_{s}^{g}\right) r_{s}^{c}+\lambda_{s}$ in the previous two equations can be replaced with $u^{\prime}\left(C_{s}^{g}\right) r_{s}^{u}$. Further, under mild regularity conditions, the left-hand sides of these equations equal $P_{t}^{i} u^{\prime}\left(C_{t}^{g}\right)$.

The proposition follows from the fact that the right-hand side of the Equation (B.19) is a monotonic function of $y_{v} m_{v}^{i}$ for all $v \geq t$.

Proof of Proposition 6. We first derive the dynamics of the state variable $c^{b}$ and the consumption dynamics more generally. Then, we derive the dependence of the endogenous variables on the state variables and the exogenous variables.

The dynamics of agent $b$ 's consumption $C^{b}$ follows from $C^{b}=\rho W^{b}$ and the dynamics for $W^{b}$ given in (6):

$$
d C^{b}=C^{b}\left(\left(r^{c}-\rho+\phi \kappa\right) d t+\phi d w_{t}\right)
$$

where $\phi \equiv \sigma \theta^{b}$ is notation for the equilibrium volatility of agent $b$ 's wealth. Using this, the dynamics of the consumption ratio $c^{b}=C^{b} / C$ are seen to be

$$
d c^{b}=c^{b}\left(\left(r^{c}-\rho+\phi \kappa-\mu^{C}-\sigma^{C} \phi+\left(\sigma^{C}\right)^{2}\right) d t+\left(\phi-\sigma^{C}\right) d w_{t}\right),
$$


while agent $a$ 's consumption dynamics $C^{a}=C-C^{b}$ are

$$
\begin{aligned}
d C^{a} & =\left(C \mu^{C}-C^{b}\left(r^{c}-\rho+\phi \kappa\right)\right) d t+\left(C \sigma^{C}-C^{b} \phi\right) d w_{t} \\
& =C\left(\mu^{C}-c^{b}\left(r^{c}-\rho+\phi \kappa\right)\right) d t+C\left(\sigma^{C}-c^{b} \phi\right) d w_{t} .
\end{aligned}
$$

The interest rate is $r_{t}^{c}=-\mu_{t}^{\xi}$ (as seen in (B.8) above) and thus applying Ito's Lemma to the marginal utility $\xi$ from (B.3) implies

$$
r^{c}=\rho+\left(\gamma^{a} \frac{\mu^{C}-c^{b} \phi \kappa}{1-c^{b}}-\frac{1}{2} \gamma^{a}\left(\gamma^{a}+1\right)\left(\frac{\sigma^{C}-c^{b} \phi}{1-c^{b}}\right)^{2}\right) \frac{1-c^{b}}{1+\left(\gamma^{a}-1\right) c^{b}} .
$$

The ordinary differential equation (ODE) that characterizes the price-dividend ratio $\zeta\left(c^{b}\right)$ follows from the fact that (B.6) is a local martingale with zero drift:

$$
\begin{aligned}
0= & 1+\zeta\left(\mu^{C}-r_{c}-\gamma^{a} \sigma^{C}\left(1-c^{b}\right)^{-1}\left(\sigma^{C}-c^{b} \phi\right)\right)+ \\
& \zeta^{\prime}\left(r_{c}-\rho+\phi \kappa-\mu^{C}-\gamma^{a}\left(\phi-\sigma^{C}\right)\left(1-c^{b}\right)^{-1}\left(\sigma^{C}-c^{b} \phi\right)\right)+\frac{1}{2} \zeta^{\prime \prime}\left(c^{b}\right)^{2}\left(\phi-\sigma^{C}\right)^{2} .
\end{aligned}
$$

It remains to determine the values of $\kappa, \sigma$, and $\phi$ as functions of $\zeta$ and its derivatives. For this, we identify three equations for these three unknowns. First, the log-utility investor's optimal position $\theta^{b}$ maximizes

$$
(\mu-r) \theta^{b}-\frac{1}{2} \sigma^{2}\left(\theta^{b}\right)^{2}
$$

subject to $\theta^{b}<m^{-1}$. Or, expressed in terms of volatility $\phi=\sigma \theta^{b}$, he maximizes

$$
\kappa \phi-\frac{1}{2} \phi^{2}
$$

so that the optimal position is

$$
\phi=\min \left(\kappa, m^{-1} \sigma\right)=\kappa-\left(\kappa-m^{-1} \sigma\right)^{+} .
$$

Next, since agent $a$ is unconstrained with respect to the market asset and generalcollateral lending and borrowing, (B.9) gives

$$
\begin{aligned}
\kappa & =\gamma^{a} \sigma^{C^{a}} \\
& =\gamma^{a} \frac{\sigma^{C}-c^{b} \phi}{c^{a}} \\
& =\gamma^{a} \frac{\sigma^{C}-c^{b} \kappa+c^{b}\left(\kappa-m^{-1} \sigma\right)^{+}}{1-c^{b}},
\end{aligned}
$$

where the second equality is due to the expression for the volatility of $C^{a}$ in (B.23) and the third to (B.25). It follows that

$$
\begin{aligned}
\kappa & =\frac{\gamma^{a}}{1+\left(\gamma^{a}-1\right) c^{b}}\left(\sigma^{C}+c^{b}\left(\kappa-m^{-1} \sigma\right)^{+}\right) \\
& =\bar{\kappa}+\gamma c^{b}\left(\kappa-\frac{\sigma}{m}\right)^{+},
\end{aligned}
$$


with $\gamma^{-1}=c^{a}\left(\gamma^{a}\right)^{-1}+c^{b}$ as per (12) and $\bar{\kappa}=\gamma \sigma^{C}$. Equation (B.26) provides a second restriction on the three parameters that need to be calculated. The third restriction comes from the fact that the volatility $\sigma$ of the price $P_{t}=C_{t} \zeta\left(c_{t}^{b}\right)$ is given by Ito's lemma and the dynamics of $c_{t}^{b}$ in (B.21):

$$
\sigma=\sigma^{C}+\frac{\zeta^{\prime} c^{b}}{\zeta}\left(\phi-\sigma^{C}\right)
$$

To solve the system of three equations (B.25)-(B.27), $\phi$ can be eliminated right away to give

$$
\begin{aligned}
\kappa-m^{-1} \sigma & =\left(\bar{\kappa}-m^{-1} \sigma\right)+\gamma c^{b}\left(\kappa-m^{-1} \sigma\right)^{+} \\
\sigma & =\sigma^{C}+\frac{\zeta^{\prime} c^{b}}{\zeta}\left(\kappa-\sigma^{C}\right)-\frac{\zeta^{\prime} c^{b}}{\zeta}\left(\kappa-m^{-1} \sigma\right)^{+}
\end{aligned}
$$

and note that the solution $(\kappa, \sigma)$ given in the proposition is trivially true if $\kappa \leq m^{-1} \sigma$, which requires $\bar{\kappa} \leq m^{-1} \bar{\sigma}$. Suppose therefore that $\kappa-m^{-1} \sigma>0$, leaving a linear system of equations. This system can be written as

$$
\begin{aligned}
\kappa-\bar{\kappa} & =\frac{1}{1-\gamma c^{b}}\left(\bar{\kappa}-m^{-1} \sigma\right)+m^{-1} \sigma-\bar{\kappa} \\
& =\frac{\gamma c^{b}}{1-\gamma c^{b}}\left(\bar{\kappa}-m^{-1} \sigma\right) \\
\sigma-\bar{\sigma} & =-\frac{\zeta^{\prime} c^{b}}{\zeta}\left(\bar{\kappa}-m^{-1} \sigma\right),
\end{aligned}
$$

which gives (21) and (22) easily.

The boundary values for $\zeta\left(c^{b}\right)$ are its values at $c^{b}=0$ and $c^{b}=1$. These are the pricedividend ratios in the single-agent economies in which either agent $a$ or agent $b$ has all the wealth. The explicit expressions are well known:

$$
\begin{aligned}
& \zeta(0)=\left(\rho+\left(\gamma^{a}-1\right) \mu^{C}-\frac{1}{2} \gamma^{a}\left(\gamma^{a}-1\right)\left(\sigma^{C}\right)^{2}\right)^{-1} \\
& \zeta(1)=\rho^{-1} .
\end{aligned}
$$

Finally, the value of the Lagrange multiplier $\psi$ follows from the first-order condition (9), given the optimal choice $\sigma^{C^{b}}=\phi$ :

$$
\begin{aligned}
\psi & =\frac{1}{m}\left(\mu-r^{c}-\beta^{C^{b}}\right)=\frac{1}{m}\left(\mu-r^{c}-\sigma^{C^{b}} \sigma\right) \\
& =\frac{\sigma}{m}\left(\kappa-\sigma^{C^{b}}\right)=\frac{\sigma}{m}(\kappa-\phi) \\
& =\frac{\sigma}{m}\left(\kappa-\frac{\sigma}{m}\right)^{+} .
\end{aligned}
$$

Proof of Proposition 7. From Proposition 4,

$$
\mu^{i^{\prime}}=\mu+\sigma^{C}\left(\sigma^{i^{\prime}}-\sigma\right)+\psi\left(m^{i^{\prime}}-m\right),
$$


and applying Ito's lemma to $P^{i^{\prime}}=C \zeta^{i^{\prime}}\left(c^{b}\right)$ gives

$$
\begin{aligned}
\mu^{i^{\prime}} & =\frac{\zeta^{i^{\prime \prime}} c^{b}}{\zeta^{i^{\prime}}}\left(r^{c}-\rho+\phi \kappa-\mu^{C}\right)+\mu^{C}+\frac{1}{2} \frac{\zeta^{i^{\prime \prime}}\left(c^{b}\right)^{2}}{\zeta^{i^{\prime}}}\left(\phi-\sigma^{C}\right)^{2}+\frac{1}{\zeta^{i^{\prime}}} \\
\sigma^{i^{\prime}} & =\frac{\zeta^{i^{\prime \prime}} c^{b}}{\zeta^{i^{\prime}}}\left(\phi-\sigma^{C}\right)+\sigma^{C} .
\end{aligned}
$$

Together, these three equations and (B.30) yield the ODE (26). The boundary conditions are

$$
\begin{aligned}
\zeta^{i^{\prime}}(0) & =\left(y^{i^{\prime}}\right)^{-1} \\
\zeta^{i^{\prime}}(1) & =\rho^{-1},
\end{aligned}
$$

where the dividend yield $y^{i^{\prime}}=y+\mu^{i^{\prime}}-\mu=y+\psi\left(m^{i^{\prime}}-m\right)$ and $y$ is the market dividend yield at $c^{b}=0$, i.e., $y=\zeta(0)^{-1}$ from Equation (B.28).

Proof of Proposition 8. The limit price follows directly from Equation (B.28). The limit value of $\psi$ follows from (24), given that $\sigma=\sigma^{C}$ (because the market price is $C$ times a constant price-dividend ratio in the limit) and $\kappa=\gamma^{a} \sigma^{C}$, which is seen from (21) with $x=0$ and $\gamma=\gamma^{a}$.

Proof of Proposition 9. Only the risk in $C$ is priced. In the limit as $c^{b} \rightarrow 0$, all valuation ratios are constant, and therefore all covariances with the market equal $\left(\sigma^{C}\right)^{2}$, so the result follows from Proposition 4 with equal betas. 


\section{References}

Acharya, V. V., and L. H. Pedersen, 2005, "Asset Pricing with Liquidity Risk," Journal of Financial Economics, 77, 375-410.

Acharya, V. V., and S. Viswanathan, 2010, "Leverage, Moral Hazard and Liquidity," Journal of Finance, forthcoming.

Adrian, T., and H. Shin, 2009, "Liquidity and leverage," Journal of Financial Intermediation, forthcoming.

Aiyagari, S., and M. Gertler, 1999, "Overreaction of Asset Prices in General Equilibrium," Review of Economic Dynamics, 2(1), 3-35.

Allen, F., and D. Gale, 1998, "Optimal Financial Crisis," Journal of Finance, 53(4), 12451284.

— , 2004, "Financial Intermediaries and Markets," Econometrica, 72(4), 1023-1061.

— , 2005, "Financial Fragility, Liquidity, and Asset Prices," Journal of the European Economic Association, 2(6), 1015-1048.

Amihud, Y., and H. Mendelson, 1986, "Asset Pricing and the Bid-Ask Spread," Journal of Financial Economics, 17(2), 223-249.

Ashcraft, A., N. Gârleanu, and L. H. Pedersen, 2010, "Two Monetary Tools: Interest Rates and Haircuts," NBER Macroeconomics Annual, forthcoming.

Basak, S., and B. Croitoru, 2000, "Equilibrium mispricing in a capital market with portfolio constraints," Review of Financial Studies, 13(3), 715-748.

— , 2006, "On the role of arbitrageurs in rational markets," Journal of Financial Economics, 81(1), 143-173.

Bernanke, B., and M. Gertler, 1989, "Agency Costs, Net Worth, and Business Fluctuations," American Economic Review, 79(1), 14-31.

Bhamra, H., and R. Uppal, 2007, "The Effect of Introducing a Non-Redundant Derivative On the Volatility of Stock-Market Returns When Agents Differ in Risk Aversion," Review of Financial Studies.

Breeden, D., 1979, "An intertemporal asset pricing model with stochastic consumption and investment opportunities," Journal of Financial Economics, 7, 265-296.

Brunnermeier, M., and L. H. Pedersen, 2009, "Market Liquidity and Funding Liquidity," 22, 2201-2238, Review of Financial Studies. 
Caballero, R., and A. Krishnamurthy, 2001, "International and domestic collateral constraints in a model of emerging market crises," Journal of Monetary Economics, 48(3), $513-548$.

Chabakauri, G., 2010, "Asset Pricing with Heterogeneous Investors and Portfolio Constraints," Working Paper, London School of Economics.

Chan, Y., and L. Kogan, 2002, "Catching up with the Joneses: Heterogeneous preferences and the dynamics of asset prices," Journal of Political Economy, 110(6), 1255-1285.

Coen-Pirani, D., 2005, "Margin requirements and equilibrium asset prices," Journal of Monetary Economics, 52(2), 449-475.

Coffey, N., W. Hrung, H.-L. Nguyen, and A. Sarkar, 2009, "Credit Risk, Liquidity Risk and Deviations from Covered Interest Rate Parity," Working paper, Federal Reserve Bank of New York.

Cuoco, D., 1997, "Optimal consumption and equilibrium prices with portfolio constraints and stochastic income," Journal of Economic Theory, 72(1), 33-73.

Cvitanić, J., and I. Karatzas, 1993, "Hedging contingent claims with constrained portfolios," The Annals of Applied Probability, 3, 652-681.

Danielsson, J., H. Shin, and J. Zigrand, 2009, "Risk Appetite and Endogenous Risk," London School of Economics, working paper.

Detemple, J., and S. Murthy, 1997, "Equilibrium asset prices and no-arbitrage with portfolio constraints," Review of Financial Studies, pp. 1133-1174.

Duffie, D., 2001, Dynamic Asset Pricing Theory. Princeton University Press, Princeton, NJ, 3rd edn.

Duffie, D., N. Gârleanu, and L. H. Pedersen, 2005, "Over-the-Counter Markets," Econometrica, $73,1815-1847$.

_ 2007, "Valuation in Over-the-Counter Markets," Review of Financial Studies, 20, $1865-1900$.

Dumas, B., 1989, "Two-person dynamic equilibrium in the capital market," Review of Financial Studies, pp. 157-188.

Fostel, A., and J. Geanakoplos, 2008, "Leverage Cycles and the Anxious Economy," American Economic Review, 98(4), 1211-1244.

Gârleanu, N., and S. Panageas, 2008, "Young, Old, Conservative and Bold: The Implications of Heterogeneity and Finite Lives for Asset Pricing," working paper, Berkeley. 
Gârleanu, N., L. H. Pedersen, and A. Poteshman, 2009, "Demand-Based Option Pricing," Review of Financial Studies, 22, 4259-99.

Geanakoplos, J., 1997, "Promises, Promises," in The Economy as an Evolving Complex System II, ed. by W. B. Arthur, S. N. Durlauf, and D. A. Lane. Addison Wesley Longman, Reading, MA, pp. 285-320.

_, 2003 , "Liquidity, Default and Crashes: Endogenous Contracts in General Equilibrium," in Advances in Economics and Econometrics: Theory and Applications II, Econometric Society Monographs: Eighth World Congress, ed. by M. Dewatripont, L. P. Hansen, and S. J. Turnovsky. Cambridge University Press, Cambridge, UK, vol. 2, pp. 170-205.

Gorton, G., and A. Metrick, 2009a, "Haircuts," Yale, working paper.

— , 2009b, "Securitized Banking and the Run on Repo," Yale, working paper.

Gromb, D., and D. Vayanos, 2002, "Equilibrium and Welfare in Markets with Financially Constrained Arbitrageurs," Journal of Financial Economics, 66(2-3), 361-407.

He, Z., and A. Krishnamurthy, 2008, "Intermediary Asset Prices," Working Paper, Northwestern University.

Hindy, A., 1995, "Viable Prices in Financial Markets with Solvency Constraints," Journal of Mathematical Economics, 24(2), 105-135.

Hindy, A., and M. Huang, 1995, "Asset pricing with linear collateral constraints," Stanford, Working paper.

Holmström, B., and J. Tirole, 1998, "Private and Public Supply of Liquidity," Journal of Political Economy, 106(1), 1-39.

—_ 2001, "LAPM: A Liquidity-Based Asset Pricing Model," Journal of Finance, 56(5), $1837-1867$.

Kiyotaki, N., and J. Moore, 1997, "Credit Cycles," Journal of Political Economy, 105(2), 211-248.

Li, T., 2008, "Margin Requirements and Stock Price Volatility When Agents' Beliefs are Heterogeneous," Working Paper, City University of Hong Kong.

Longstaff, F., 2004, "The Flight-to-Liquidity Premium in US Treasury Bond Prices," The Journal of Business, 77(3), 511-526.

Longstaff, F., and J. Wang, 2009, "Asset Pricing and the Credit Market," working paper, $U C L A$.

Lustig, H., and S. Van Nieuwerburgh, 2005, "Housing collateral, consumption insurance, and risk premia: An empirical perspective," Journal of Finance, pp. 1167-1219. 
Mitchell, M., L. H. Pedersen, and T. Pulvino, 2007, "Slow Moving Capital," American Economic Review, 97(2), 215-220.

Prieto, R., 2010, "Dynamic Equilibrium with Heterogeneous Agents and Risk Constraints," Working Paper, Swiss Finance Institute and EPFL.

Rytchkov, O., 2009, "Dynamic Margin Constraints," Working paper, Temple University.

Shleifer, A., and R. W. Vishny, 1997, "The Limits of Arbitrage," Journal of Finance, 52(1), $35-55$.

Vayanos, D., and P.-O. Weill, 2008, "A Search-Based Theory of The On-The-Run Phenomenon," Journal of Finance, 63, 1351-89.

Wang, J., 1996, "The term structure of interest rates in a pure exchange economy with heterogeneous investors," Journal of Financial Economics, 41(1), 75-110.

Weinbaum, D., 2009, "Investor Heterogeneity, Asset Pricing and Volatility Dynamics," working paper, Cornell. 


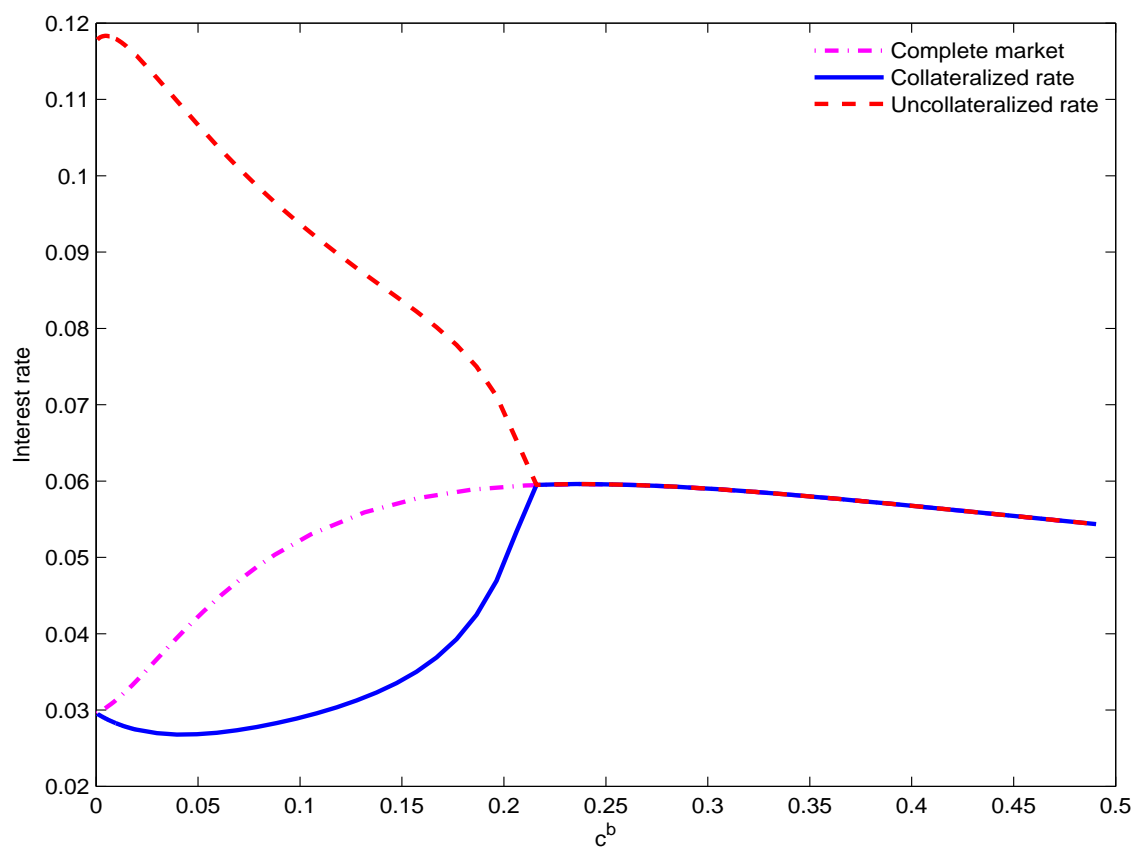

Figure 1: Collateralized and Uncollateralized Interest rates. This figures shows how interest rates depend on the state of the economy as measured by $c^{b}$ the fraction of consumption accruing to the risk tolerant investor. Low values of $c^{b}$ correspond to bad states of the economy, and margin requirements bind for $c^{b} \leq 0.22$. The solid line represents the collateralized interest rate $r^{c}$ (or Treasury rate), which drops sharply in bad times. The dashed line represents the uncollateralized inter-bank interest rate $r^{u}$. As a frictionless benchmark, the dash-dot line represents the interest rate obtaining in an economy without any constraints. 


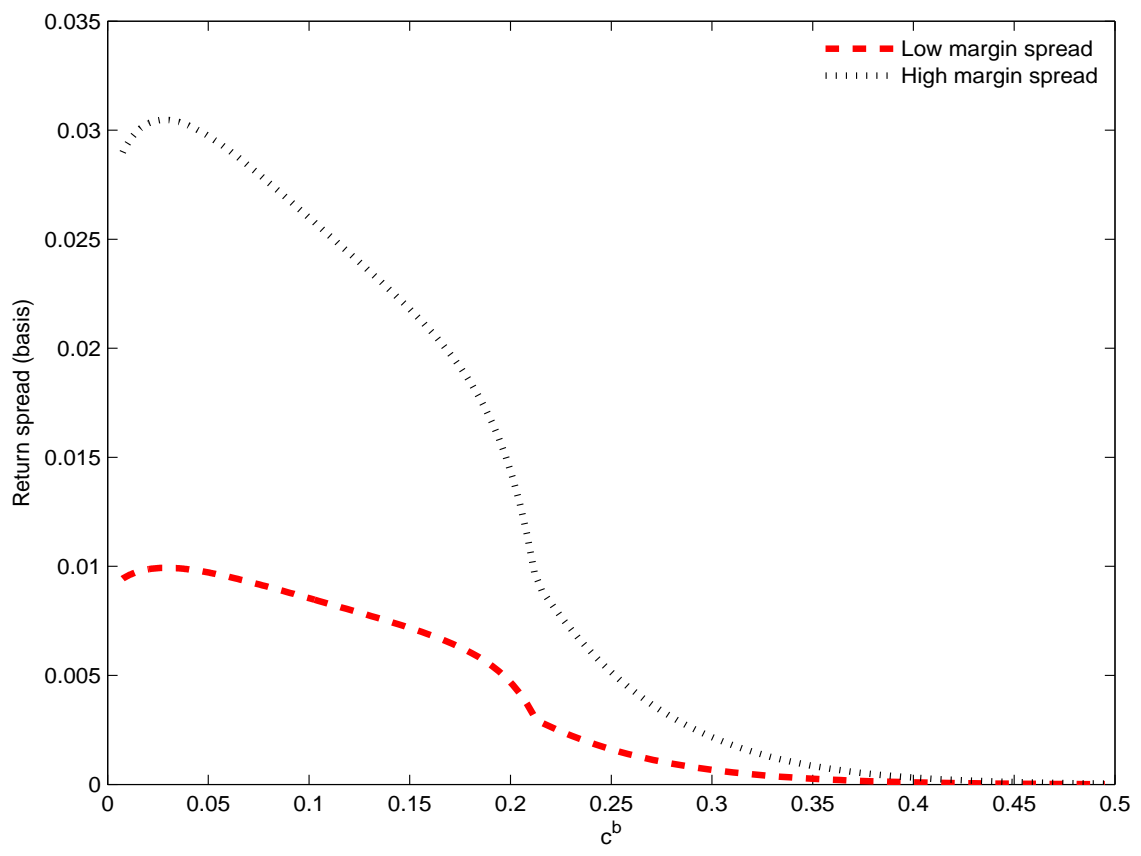

Figure 2: Deviations from the Law of One Price (Basis). This figure shows the difference between the expected return of an underlying security and a derivative with the same cash flows and a lower margin. This return spread is depicted as a function of the state of the economy as measured by $c^{b}$ (where a low $c^{b}$ is a bad state of the economy). The dotted line represents the return spread for a low-margin derivative $m^{\text {low }}$ with a high margin spread $m^{\text {underlying }}-m^{\text {low }}=30 \%$, and the dashed line represents a medium-margin derivative with a smaller margin spread of $m^{\text {underlying }}-m^{\text {medium }}=10 \%$. 


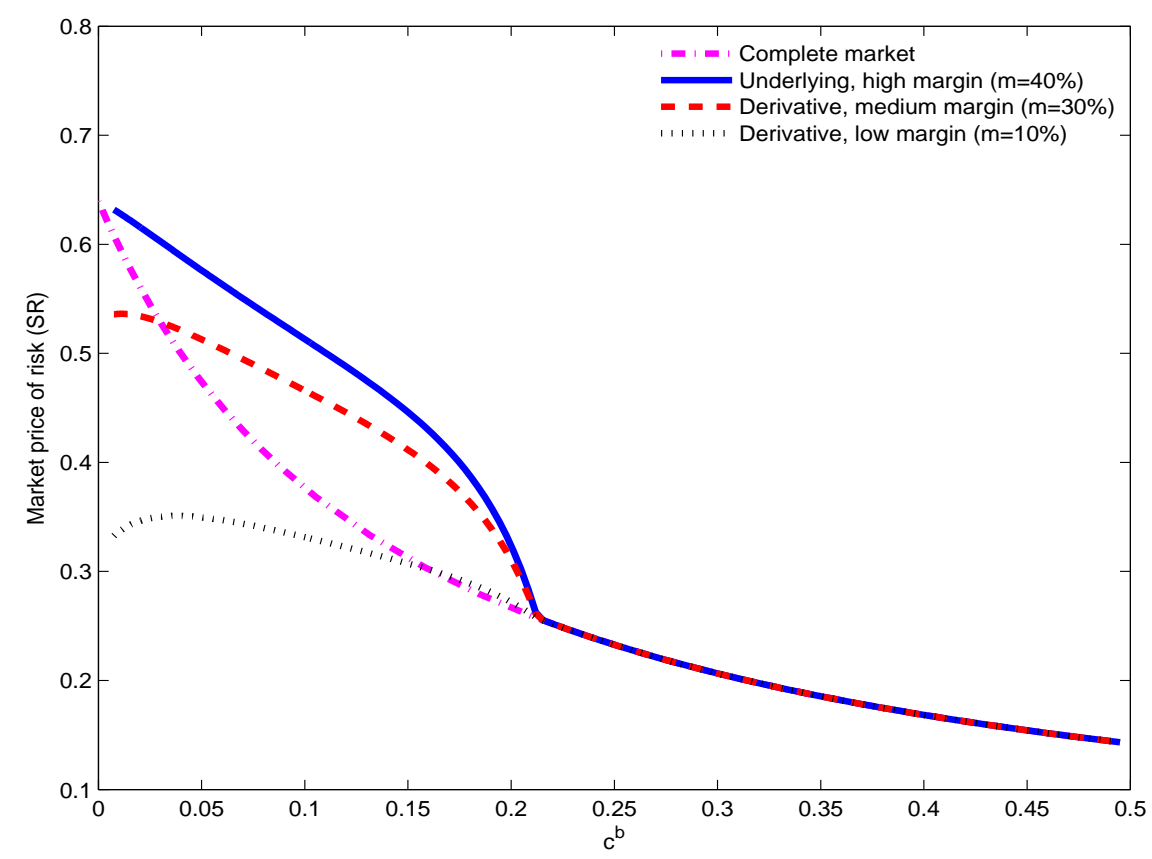

Figure 3: Sharpe Ratios (SR). The figure shows how the required SR depends on the state of the economy as measured by $c^{b}$ (where a low $c^{b}$ is a bad state of the economy). The solid line represents the SR of the underlying asset with a high margin, the dashed line represents the SR of a derivative with identical cash flows and a medium margin, and the dotted line that of a derivative with a low margin. As a frictionless benchmark, the dash-dot line represents the SR obtaining in an economy without any constraints. 


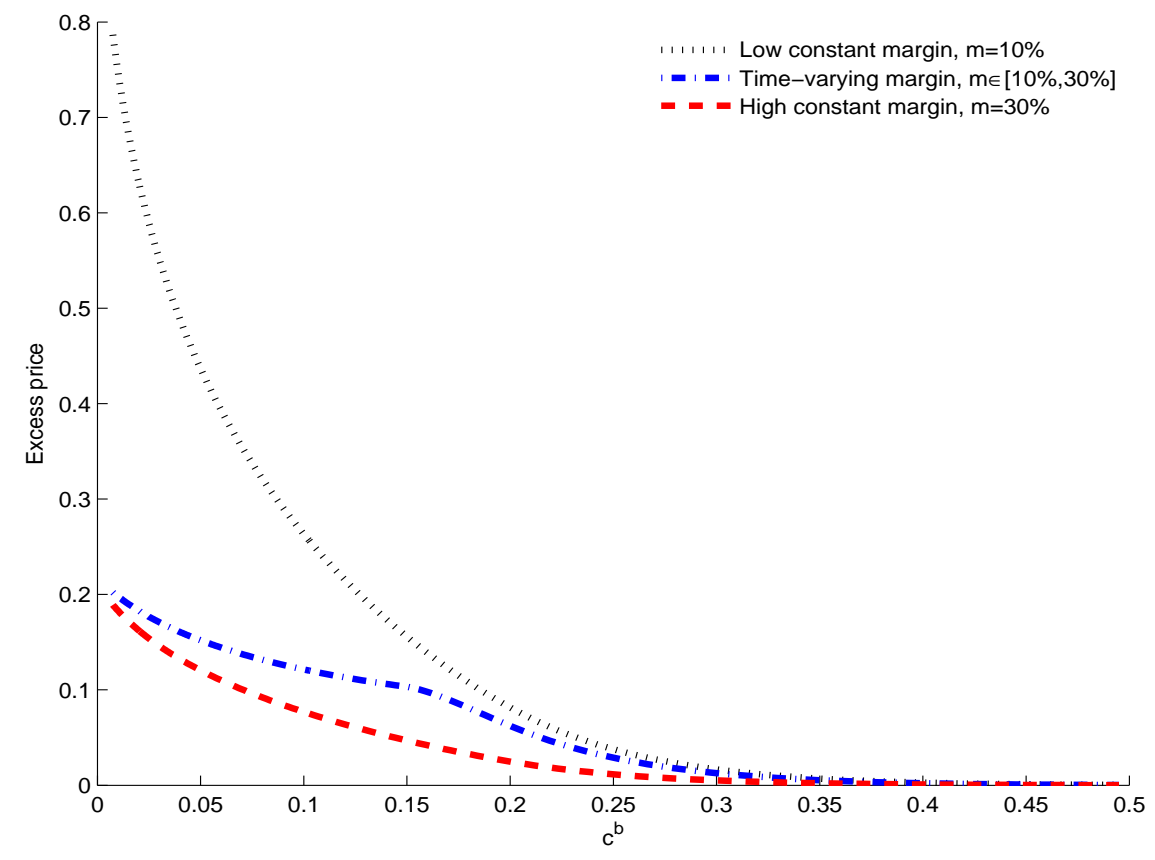

Figure 4: Price Premium. The figure shows how the price premium above the price of the underlying depends on the state of the economy as measured by $c^{b}$ (where a low $c^{b}$ is a bad state of the economy). Each derivative has the same cash flows as the underlying, but a lower margin requirement and, therefore, a larger price. The price premium, $P^{\text {derivative }} / P^{\text {underlying }}$ 1 , is illustrated for a derivative with a low constant margin of $10 \%$, one with a margin of $30 \%$, and one that has a margin that increases from $10 \%$ to $30 \%$ in a bad state of the economy with $c^{b}<0.15$. The price premium is especially large for low margin securities during bad economic times, but is non-trivial even before margin requirements bind $\left(c^{b}>0.22\right)$ due to the risk of future binding constraints. 


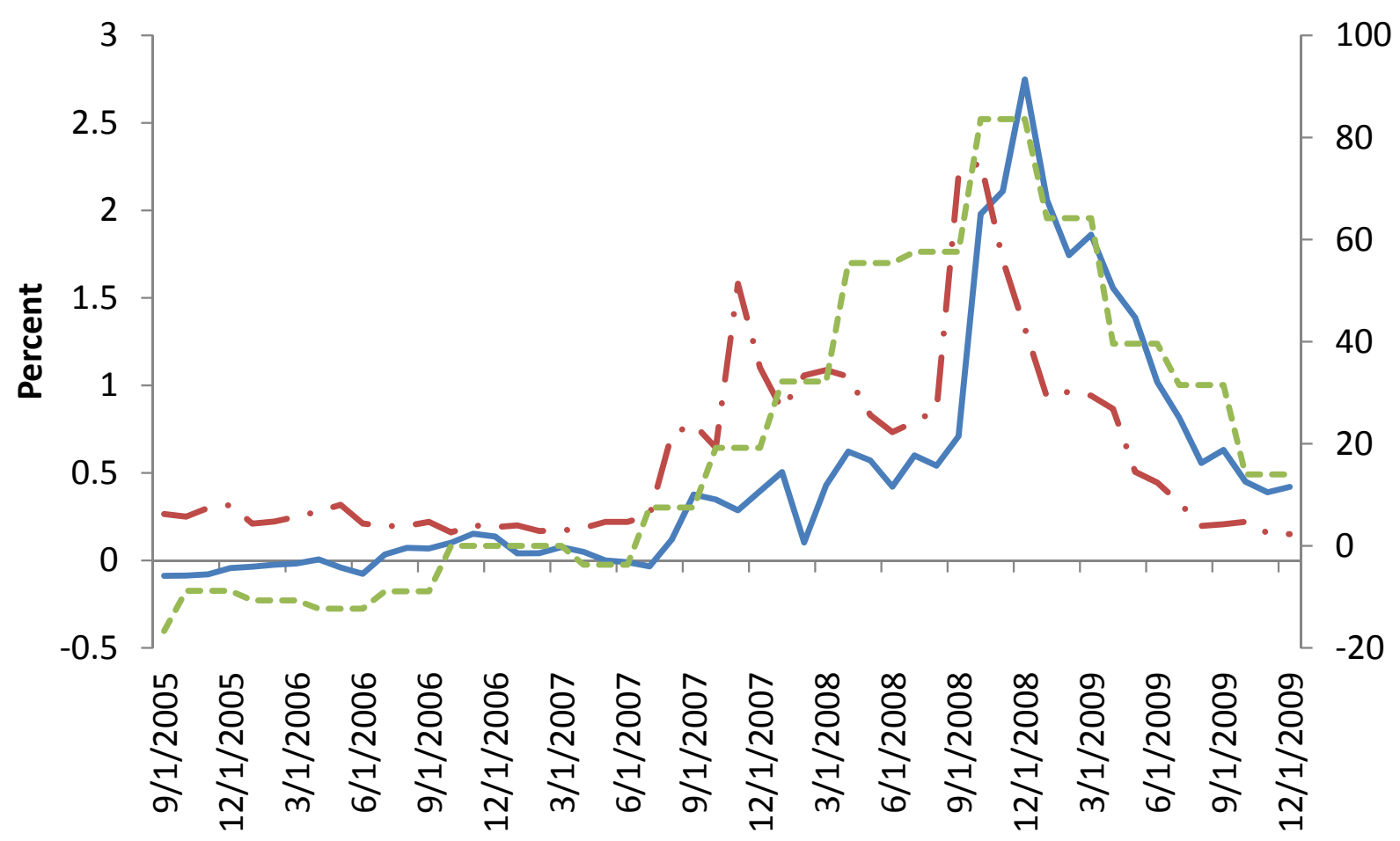

_IG Basis —- LIBOR - GC repo - -- Tightening credit standards (right axis)

Figure 5: The CDS-Bond basis, the LIBOR-GC repo Spread, and Credit Standards. This figure shows the CDS-bond basis, computed as the yield spread for corporate bonds minus the CDS spread (adjusted to account for certain differences between CDS and bonds), averaged across high grade bonds, as well as the spread between the 3-month uncollateralized LIBOR loans and 3-month general collateral (GC) repo rate, and the net percent of respondents tightening their credit standards in the Federal Reserve Board's "Senior Loan Officer Opinion Survey on Bank Lending Practices". Consistent with our model's predictions, tighter credit is associated with higher interest-rate spreads and a widening of the basis. 


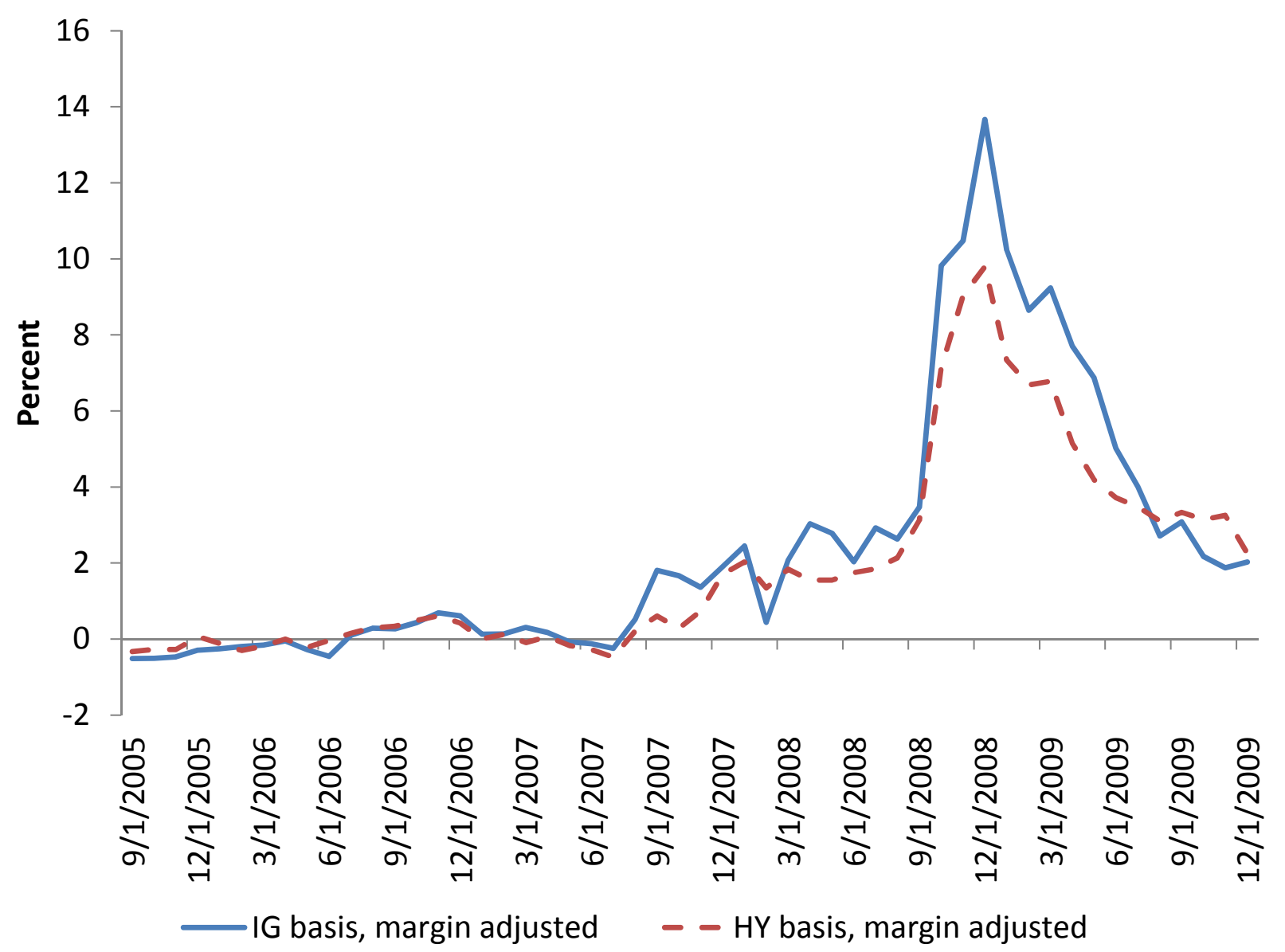

Figure 6: Investment Grade (IG) and High Yield (HY) CDS-Bond Bases, Adjusted for Their Margins. This figure shows the CDS-bond basis, computed as the yield spread for corporate bonds minus the CDS spread (adjusted to account for certain differences between CDS and bonds), averaged across IG and HY bonds, respectively. Our model predicts that the basis should line up in the cross section according to the margin differences. Since IG corporate bonds have a margin around 25\% and IG CDS have margins around 5\%, the IG margin differential is $20 \%$. Hence, the adjusted IG basis is basis/0.20. Similarly, we estimate that the HY margin differential is around $50 \%$ so the HY adjusted basis is basis/0.50. We adjust the level of each series by subtracting the average during the first two years 2005-2006 when credit was easy so margin effects played a small role. Consistent with the idea that the expected profit per margin use is constant in the cross section, we see that the adjusted basis track each other. 


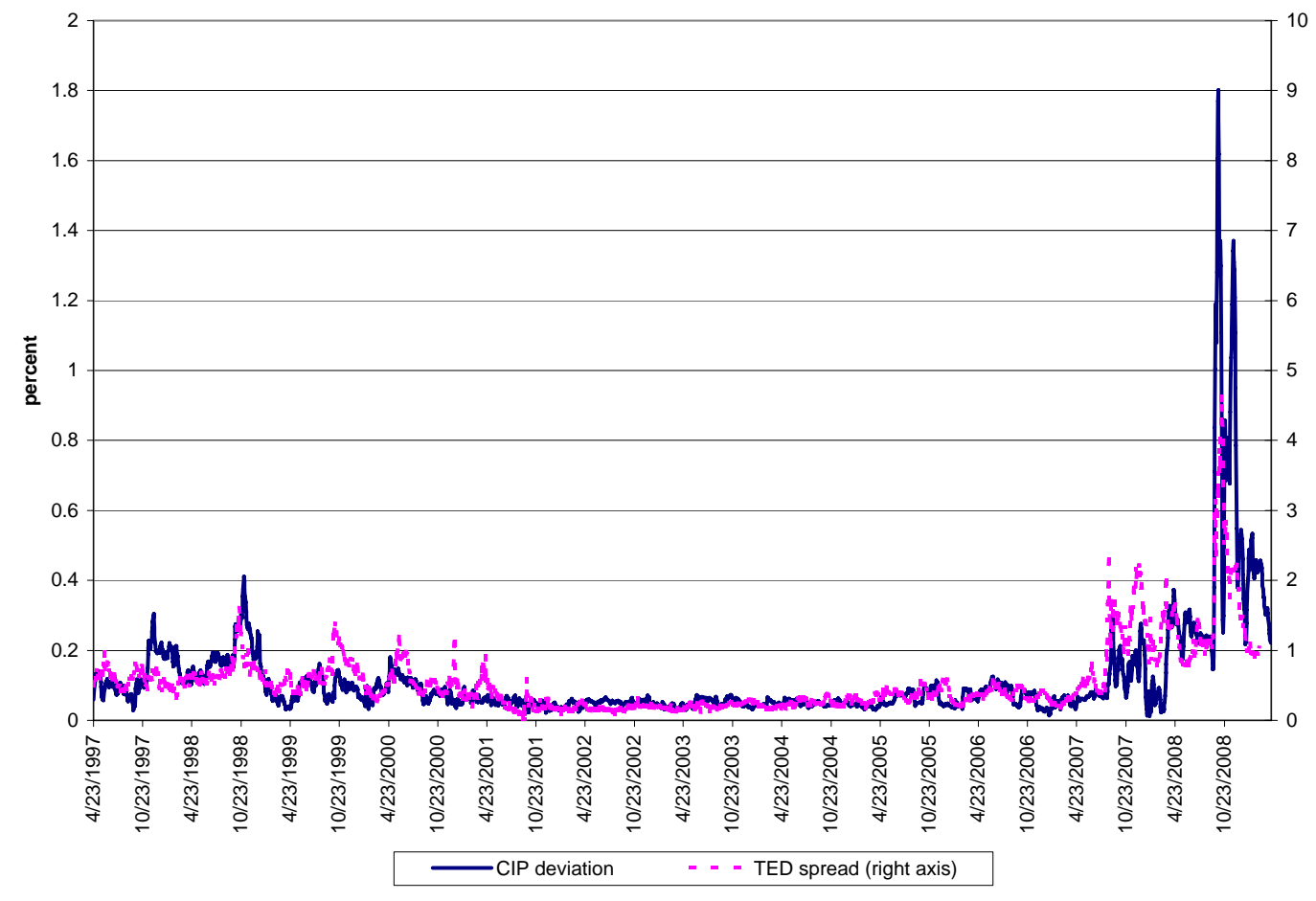

Figure 7: Average Deviation from Covered-Interest Parity and the TED Spread. This figure shows the average absolute deviation from the covered interest rate parity for the Euro, Yen, and British Pound, as well as the TED spread, which is the 3-month uncollateralized LIBOR rate minus the 3-month T-bill rate. The magnitude of the deviation from the CIP tracks the TED spread in the time series consistent with the model's prediction that the shadow cost of funding liquidity due to binding margins drive both effects. 
Table 2: Time-Series Relation Between CDS-Bond Basis and Measures on Liquidity and Risk Premia. The table reports univariate regressions of the CDS-bond basis on, respectively, the TED-spread (proxying for funding illiquidity) and the dividend yield of U.S. stocks as reported by MSCI (proxying for risk premia), monthly from 2005 to 2009, and the tightening credit standards from Federal Reserve Board's survey, which is available quarter. We run these regressions separately for the average basis among investment-grade and high-yield bonds, and separately for the levels of these variables (Panel A) and the monthly changes of the variables (Panel B), except the credit standards which is run quarterly. To account for the potential bias due to stale prices in the monthly regression of changes, we include a lagged value of the explanatory variable (Dimson (1979)), basis $s_{t}=\alpha+\beta_{1} x_{t}+\beta_{2} x_{t-1}+\varepsilon_{t}$. We report the bias-corrected estimate, $\beta_{1}+\beta_{2}$. The coefficient of the intercept is not reported.

Panel A: Regressions in Levels. Dependent Variable: CDS-Bond Basis.

\begin{tabular}{|c|c|c|c|c|c|c|}
\hline & \multicolumn{3}{|c|}{ Investment Grade } & \multicolumn{3}{|c|}{ High Yield } \\
\hline & coefficient & t-statistic & $\mathrm{R} 2$ & coefficient & t-statistic & R2 \\
\hline TED spread & 0.54 & 4.62 & $26 \%$ & 0.86 & 3.78 & $19 \%$ \\
\hline Credit standards & 0.02 & 13.60 & $75 \%$ & 0.03 & 11.11 & $67 \%$ \\
\hline Dividend yield & 1.62 & 21.03 & $88 \%$ & 2.95 & 17.34 & $83 \%$ \\
\hline
\end{tabular}

Panel B: Regressions in Changes. Dependent Variable: CDS-Bond Basis.

\begin{tabular}{|c|c|c|c|c|c|c|}
\hline & \multicolumn{3}{|c|}{ Investment Grade } & \multicolumn{3}{|c|}{ High Yield } \\
\hline & coefficient & t-statistic & $\mathrm{R} 2$ & coefficient & t-statistic & $\mathrm{R} 2$ \\
\hline TED spread & 0.42 & 4.35 & $42 \%$ & 0.72 & 4.32 & $33 \%$ \\
\hline Credit standards & 0.02 & 4.12 & $47 \%$ & 0.03 & 3.17 & $35 \%$ \\
\hline Dividend yield & 1.06 & 3.83 & $23 \%$ & 2.37 & 5.99 & $39 \%$ \\
\hline
\end{tabular}


Table 3: Cross-Sectional Relation Between IG and HY Bases. Panel A reports the regression of the high-yield (HY) CDS-bond basis on the investment-grade (IG) CDS-bond basis. We note that the IG securities is more liquid, and, to account for the potential effect of stale prices in the regression of changes, we include a lagged value of the explanatory variable (Dimson (1979)), basis ${ }_{t}^{H Y}=\alpha+\beta_{1}$ basis $_{t}^{I G}+\beta_{2}$ basis $_{t-1}^{I G}+\varepsilon_{t}$. We report the biascorrected estimate, . In Panel B, we first estimate the slope of the cross-sectional required return-margin relation at any time. We do this by regressing the two bases on the two corresponding margin differences $(0.20,0.50)$. We then regress this slope (which measures funding illiquidity according to the model) on the three explanatory variables described in Table 2.

Panel A: Regressing the high-yield basis on the investment-grade basis.

\begin{tabular}{lccc}
\hline & coefficient & t-statistic & R2 \\
\hline Levels & & & \\
\hline IG basis, levels & 1.79 & 25.53 & $91 \%$ \\
Changes & & & \\
\hline IG basis, changes & 1.42 & 8.27 & $64 \%$ \\
\hline
\end{tabular}

Panel B: Regressing the slope of the margin-return curve on explanatory variables.

\begin{tabular}{lccc}
\hline & coefficient & t-statistic & R2 \\
\hline Levels & & & \\
\hline TED spread & 1.86 & 3.95 & $20 \%$ \\
Credit standards & 0.07 & 11.71 & $69 \%$ \\
Dividend yield & 6.19 & 18.61 & $85 \%$ \\
Changes & & & \\
\hline TED spread & 1.53 & 4.54 & $37 \%$ \\
Credit standards & 0.07 & 3.39 & $38 \%$ \\
Dividend yield & 4.81 & 5.78 & $38 \%$ \\
\hline
\end{tabular}


Table 4: Volatility of CDS vs. Bonds. The table shows the annualized return volatility of CDS and bonds estimated over, respectively, the early pre-crisis sample (9/2005-6/2007), the crisis sample (7/2007-12/2009), and the full sample. The table reports this separately for investment-grade and high-yield securities. In both cases, CDS and bonds are about equally volatile in the early sample, but bonds are more volatile during the crisis, consistent with the model's predictions that high-margin bonds have more funding liquidity risk.

\begin{tabular}{|c|c|c|c|c|}
\hline & \multicolumn{2}{|c|}{ Investment Grade } & \multicolumn{2}{|c|}{ High Yield } \\
\hline & $\mathrm{CDS}$ & Bonds & $\mathrm{CDS}$ & Bonds \\
\hline Early sample & $0.57 \%$ & $0.51 \%$ & $3.73 \%$ & $2.76 \%$ \\
\hline Crisis & $3.92 \%$ & $10.26 \%$ & $17.19 \%$ & $20.87 \%$ \\
\hline Full sample & $3.02 \%$ & $7.83 \%$ & $13.31 \%$ & $16.01 \%$ \\
\hline
\end{tabular}


Table 5: Betas of CDS vs. Bonds. Panel A shows the market betas of CDS and bond returns estimated over, respectively, the early pre-crisis sample (9/2005-6/2007), the crisis sample (7/2007-12/2009), and the full sample. The table reports this separately for investment-grade and high-yield securities. In both cases, bonds have slightly lower betas in the early sample, but bonds have larger betas during the crisis, consistent with the model's predictions that high-margin bonds have more funding liquidity risk. Panel B shows the statistical significance of the difference between CDS and bonds using a panel regression.

Panel A: Betas estimated separately for CDS on Bonds

\begin{tabular}{ccccccc}
\hline & \multicolumn{2}{c}{ Investment Grade } & & \multicolumn{2}{c}{ High Yield } \\
\cline { 2 - 3 } \cline { 5 - 6 } \cline { 5 - 6 } \cline { 5 - 6 } Early sample & CDS & Bonds & & CDS & Bonds \\
\cline { 2 - 3 } \cline { 5 - 6 } (stand. err.) & 0.05 & -0.01 & & 0.35 & 0.22 \\
Crisis & $(0.01)$ & $(0.02)$ & & $(0.09)$ & $(0.08)$ \\
(stand. err.) & 0.13 & 0.29 & & 0.56 & 0.73 \\
Full sample & $(0.02)$ & $(0.07)$ & & $(0.10)$ & $(0.12)$ \\
(stand. err.) & 0.12 & 0.26 & & 0.54 & 0.69 \\
& $(0.02)$ & $(0.05)$ & & $(0.08)$ & $(0.09)$ \\
\hline
\end{tabular}

Panel B: Panel regression with CDS and bonds

$$
r_{t}^{i}=\alpha+\bar{\alpha} \cdot 1_{[i=b o n d]}+\beta r_{t}^{M K T}+\bar{\beta} r_{t}^{M K T} \cdot 1_{[i=b o n d]}+\varepsilon_{t}^{i}
$$

\begin{tabular}{lccc}
\hline & Investment Grade & & High Yield \\
\cline { 2 - 3 } MKT & 0.12 & 0.54 \\
(t-statistic) & $(3.17)$ & $(6.48)$ \\
MKT*1(Bond) $^{*}$ & 0.14 & 0.15 \\
(t-statistic) & $(2.60)$ & $(1.28)$ \\
\hline
\end{tabular}

